OPEN ACCESS

Edited by:

Agustín González,

Complutense University of Madrid,

Spain

Reviewed by:

Christopher J. Winrow,

Ironwood Pharmaceuticals,

United States

Eric Murillo-Rodriguez, Anahuac Mayab University, Mexico

Giorgio Roberto Merlo,

Dipartimento di Biotecnologie

Molecolari e Scienze per la salute,

Università degli Studi di Torino, Italy

*Correspondence:

Marina Paolucci

paolucci@unisannio.it

Received: 15 April 2018 Accepted: 11 July 2018

Published: 30 July 2018

Citation: Imperatore R, D'Angelo L, Safari O, Motlagh HA, Piscitelli F, de Girolamo P, Cristino L, Varricchio E, di Marzo $V$ and Paolucci M (2018) Overlapping Distribution of Orexin and Endocannabinoid Receptors and Their Functional Interaction in the Brain of Adult Zebrafish Front. Neuroanat. 12:62. doi: 10.3389/fnana.2018.00062

\section{Overlapping Distribution of Orexin and Endocannabinoid Receptors and Their Functional Interaction in the Brain of Adult Zebrafish}

\author{
Roberta Imperatore ${ }^{1,2}$, Livia D'Angelo ${ }^{3,4}$, Omid Safari ${ }^{5}$, Hamidreza Ahmadniaye Motlagh ${ }^{5}$, \\ Fabiana Piscitelli ${ }^{2}$, Paolo de Girolamo ${ }^{3}$, Luigia Cristino $^{2}$, Ettore Varricchio ${ }^{1}$, \\ Vincenzo di Marzo ${ }^{2}$ and Marina Paolucci ${ }^{1 *}$

\begin{abstract}
${ }^{1}$ Department of Science and Technology (DST), University of Sannio, Benevento, Italy, ${ }^{2}$ Endocannabinoid Research Group, Institute of Biomolecular Chemistry, Pozzuoli, Italy, ${ }^{3}$ Department of Veterinary Medicine and Animal Productions, University of Naples Federico II, Naples, Italy, ${ }^{4}$ Stazione Zoologica Anton Dohrn, Naples, Italy, ${ }^{5}$ Department of Fisheries, Faculty of Natural Resources and Environment, Ferdowsi University of Mashhad, Mashhad, Iran
\end{abstract}

Hypocretins/Orexins neuropeptides are known to regulate numerous physiological functions, such as energy homeostasis, food intake, sleep/wake cycle, arousal and wakefulness, in vertebrates. Previous studies on mice have revealed an intriguing orexins/endocannabinoids (ECs) signaling interaction at both structural and functional levels, with OX-A behaving as a strong enhancer of 2-arachydonoyl-glycerol (2-AG) biosynthesis. In this study, we describe, for the first time in the brain of zebrafish, the anatomical distribution and co-expression of orexin (OX-2R) and endocannabinoid (CB1R) receptors, suggesting a functional interaction. The immunohistochemical colocalization of these receptors by confocal imaging in the dorsal and ventral telencephalon, suprachiasmatic nucleus (SC), thalamus, hypothalamus, preoptic area (PO) and cerebellum, is reported. Moreover, biochemical quantification of 2-AG levels by LC-MS supports the occurrence of OX-A-induced 2-AG biosynthesis in the zebrafish brain after $3 \mathrm{~h}$ of OX-A intraperitoneal (i.p.; $3 \mathrm{pmol} / \mathrm{g}$ ) or intracerebroventricular (i.c.v.; $0.3 \mathrm{pmol} / \mathrm{g}$ ) injection. This effect is likely mediated by $\mathrm{OX}-2 \mathrm{R}$ as it is counteracted by i.p./i.c.v administration of OX-2R antagonist (SB334867, $10 \mathrm{pmol} / \mathrm{g}$ ). This study provides compelling morphological and functional evidence of an OX-2R/CB1R signaling interaction in the brain of adult zebrafish, suggesting the use of this well-established vertebrate animal model for the study of complex and phylogenetically conserved physiological functions.

Keywords: orexin/hypocretin receptor OX-2R, cannabinoid receptor (CB1R), confocal microscopy, endocannabinoid levels, zebrafish brain

\section{INTRODUCTION}

The high physiological and genetic homology to mammals, as well as the highly conserved anatomical and cytoarchitectural organization have made zebrafish (Danio rerio) a very useful animal model in the neuroscience to analyze both brain functions and dysfunctions (Haffter and Nüsslein-Volhard, 1996; Norton and Bally-Cuif, 2010; Wolman and Granato, 2012; 
Leung et al., 2013; Varshney and Burgess, 2014; D’Angelo et al., 2016b). Neuroanatomical evidence indicates that, for example, components of the zebrafish telencephalon are homologous to the mammalian hippocampus and amygdala, while the midbrain tectum shows similar organization to the cortex of amniotes (Kesavan et al., 2017) or to superior colliculus of mammals (Heap et al., 2018). These highly conserved brain areas are also involved in the control of emotion, learning, memory and movements as in mammals (Wullimann and Mueller, 2004; Broglio et al., 2005; Mueller and Wullimann, 2009; Kesavan et al., 2017).

The orexins are neuropeptides derived from a common precursor, pre-pro-orexin, which is highly conserved in the phylogenetic scale (Sakurai et al., 1998; Shibahara et al., 1999; Galas et al., 2001; Alvarez and Sutcliffe, 2002; Ohkubo et al., 2002; Kaslin et al., 2004; Panula, 2010; Wong et al., 2011). The orexin gene was cloned in zebrafish in 2004 (Kaslin et al., 2004) and it shows a structure very similar to that of mammals, encoding for two active peptides, Orexin-A (OX-A) and Orexin-B (OX-B), homologous to those of mammalian (human, mouse, rat, pig, dog) and nonmammalian (birds, reptiles, amphibians and fish) vertebrates (Sakurai et al., 1998; Shibahara et al., 1999; Hungs et al., 2001; Ohkubo et al., 2002; Kaslin et al., 2004; Faraco et al., 2006; Xu and Volkoff, 2007; Wong et al., 2011). Moreover, a high sequence homology has been found near the C-terminus of OX peptides, which is the region involved in the receptor selectivity and is crucial for orexins biological activity (Darker et al., 2001; Lang et al., 2004; Chiu and Prober, 2013). In the adult zebrafish, as in mammals, the expression of the orexin gene has been found only in a restricted neuronal population of the lateral hypothalamus $(\mathrm{LH})$, which sends projections to most of the brain areas through the telencephalon, diencephalon, mesencephalon and rhombencephalon (Kaslin et al., 2004; Panula et al., 2010; Sundvik et al., 2011; Singh et al., 2015; Sundvik and Panula, 2015). While in mammals the orexins act binding to two specific $G$ protein-coupled receptors, orexin 1 and orexin 2 receptors (OX-1R and OX-2R; de Lecea et al., 1998; Peyron et al., 1998; Sakurai et al., 1998), only one OX receptor, corresponding structurally to the mammalian OX-2R, has been identified in zebrafish (Yokogawa et al., 2007; Wong et al., 2011). The expression of OX-2R has been reported in several brain areas of adult zebrafish, which correspond to the orexinergic neuron projection areas, such as the dorsal and ventral telencephalon, the ventromedial (VM) hypothalamus; the ventral, lateral and caudal hypothalamic nuclei; the caudal zone of the periventricular hypothalamus; the thalamic nuclei; the pretectal nuclei; the periventricular gray zone (PGZ) of optic tectum; the periventricular nucleus of posterior tuberculum; the lateral nuclei in the dorsal tectum and tegmentum, and the locus coeruleus (Kaslin et al., 2004). Several studies have reported that in zebrafish, as in mammals, the orexins signaling is involved in the regulation of many physiological functions, such as sleep/wake cycle, energy homeostasis and locomotor activity (Prober et al., 2006; Panula, 2010; Elbaz et al., 2013; Tsujino and Sakurai, 2013). The overexpression of orexins promotes wakefulness and increases locomotor activity during active state, without affecting the rhythmicity of movements (Prober et al., 2006; Yokogawa et al., 2007). Furthermore, long-term food deprivation leads to a significant increase of pre-pro-orexin mRNA levels in zebrafish and goldfish brain, while intracerebroventricular (i.c.v) injection of OX-A induces feeding, as in mammals (Novak et al., 2005; Nakamachi et al., 2006; Yokobori et al., 2011).

While a massive amount of data has been reported on the endocannabinoid system in mammals, little information exists in fish. As revealed by phylogenetic analyses, the endocannabinoid system is highly conserved between zebrafish and mammals (McPartland et al., 2007; Klee et al., 2012). The endocannabinoids (ECs), mainly the 2-arachydonoylglycerol (2-AG), act through the cannabinoid receptor 1 $(\mathrm{CB} 1 \mathrm{R})$, which represents the most plentiful G protein coupled receptor within the central nervous system (Pertwee, 1997). $\mathrm{CB} 1 \mathrm{R}$ regulates the majority of cannabinoid central actions (Herkenham et al., 1990; Piomelli, 2003) and numerous biological processes (Herkenham et al., 1990, 1991; Zou and Kumar, 2018). CB1R stimulation affects changes in food intake (Silvestri and Di Marzo, 2013; Krug and Clark, 2015) and promotes obesity, while downregulation of CB1R leads to a reduction of appetite (Osei-Hyiaman et al., 2005; GaryBobo et al., 2007; Shimada et al., 2012). CB1R mRNA expression within the zebrafish brain has been detected throughout the telencephalon, pretectum, torus longitudinalis (TL), hypothalamus, tegmentum, anterior rhombencephalon and periventricular hypothalamus, sharing homologies with mammalian CB1R distribution (Lam et al., 2006). CB1R sequence analysis shows a high degree of conservation, especially in those residues critical for ligand recognition and function in mammals (McPartland and Glass, 2003), providing strong support that the zebrafish CB1R is a functional homologous of the human.

Several studies have evidenced the ability of OX-A to potentiate $\mathrm{CB} 1 \mathrm{R}$ signaling in mammals. Indeed, the endocannabinoid 2-AG can act as paracrine or autocrine factor leading, respectively, to an $\mathrm{OX}-1 \mathrm{R} / \mathrm{CB} 1 \mathrm{R}$ physical interaction and potentiation of CB1R activity, or to a functional regulation of $\mathrm{CB} 1 \mathrm{R}$ at presynaptic level and consequent possible modulation of synaptic plasticity. By these physical and functional interactions, OX-1R and CB1R can control many physiological and pathophysiological functions (Cristino et al., 2013, 2016, 2017; Flores et al., 2013; Imperatore et al., 2016; Morello et al., 2016). Very few data are available on CB1R$\mathrm{OX}-2 \mathrm{R}$ interaction, addressing contrasting evidences on their functional interactions (Yazdi et al., 2015; Esmaeili et al., 2017). The relative simplicity of orexins signaling in the zebrafish brain, due to the low number of OX neurons and the expression of only one OX receptor, and the highly conserved ECs functions, make zebrafish an ideal animal model to study the interaction between orexins and ECs.

In this framework, the aim of our study was to investigate whether in the zebrafish brain OX-2R and CB1R show an overlapping pattern of distribution and functional interaction similar to those suggested in the mouse. These data allow us to propose zebrafish as an animal model for 


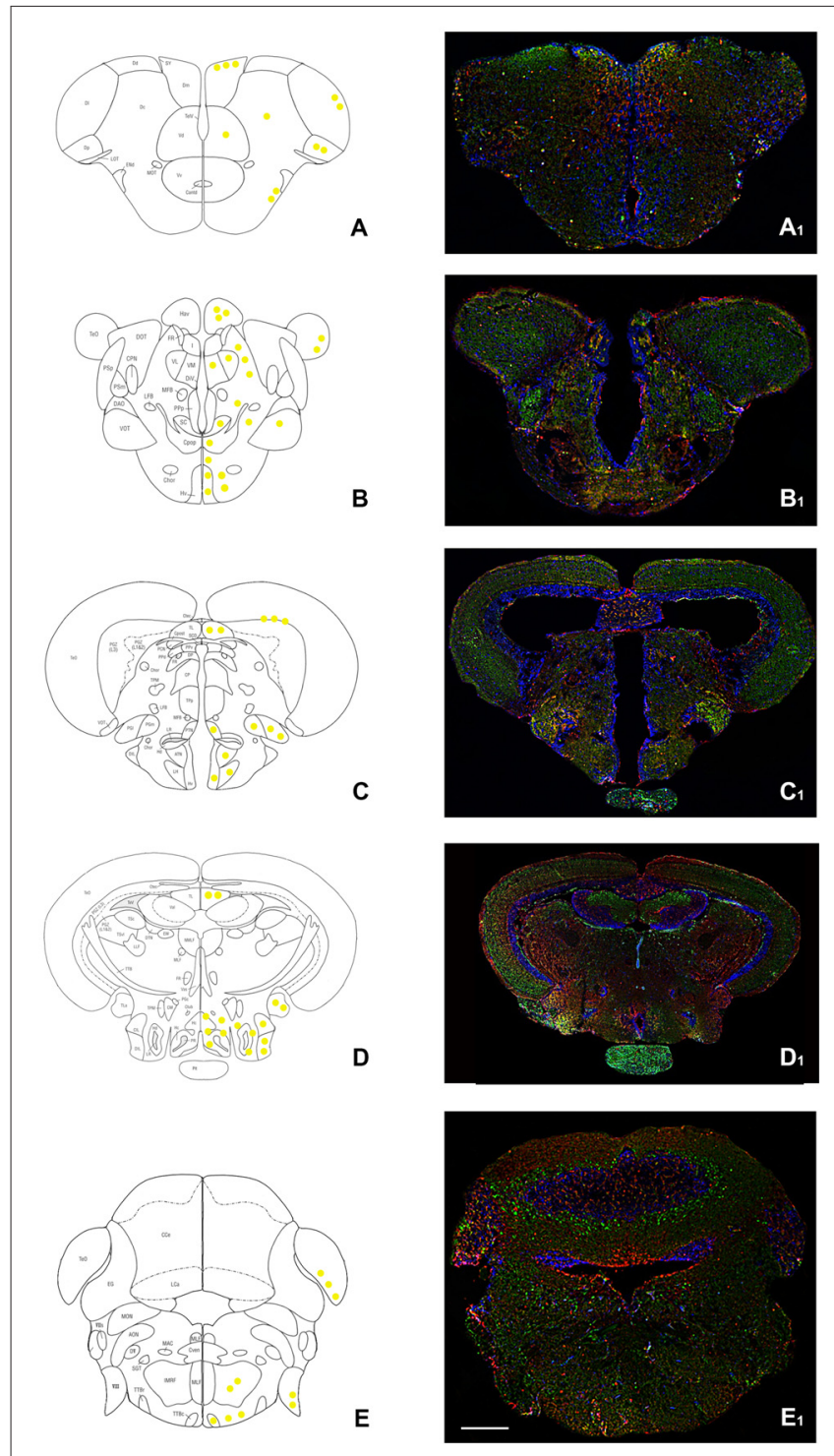

FIGURE 1 | Overview of orexin 2 receptors (OX-2R; red) and cannabinoid receptor 1 (CB1R; green) immunoreactivity in the whole adult zebrafish brain. (A-E) Schematic drawings of five coronal sections of the adult zebrafish brain showing, at right, the distribution of OX-2R/CB1R co-expression (yellow solid circles) and, at left, the brain nuclei and regions according to Wullimann et al. (1996). ( $\mathbf{A}_{\mathbf{1}}-\mathbf{E}_{\mathbf{1}}$ ) Photomicrographs of the sections corresponding to the schematic coronal sections reported in $(\mathbf{A}-\mathbf{E})$. $\left(\mathbf{A}, \mathbf{A}_{\mathbf{1}}\right)$ Telencephalon: OX-2R/CB1R co-localization in lateral (DI), medial (Dm), central (Dc) and posterior (Dp) part of the dorsal telencephalon and in the dorsal $(\mathrm{Vd})$ and lateral $(\mathrm{VI})$ part of the ventral telencephalon. $\left(\mathbf{B}, \mathbf{B}_{\mathbf{1}}\right)$ Diencephalon: OX-2R/CB1R co-localization in ventral habenular nucleus (Hav), optic tectum (TeO), ventral zone of the periventricular hypothalamus $(\mathrm{Hv}) .\left(\mathbf{C}, \mathbf{C}_{1}\right)$ Dienchephalon/mesencephalon: OX-2R/CB1R co-localization in the torus longitudinalis (TL), medial (PGm) and lateral (PGI) preglomerular nuclei, lateral hypotalamus (LH), Hv, and anterior (ATN) and posterior (PTN) tuberal nuclei. (D, $\mathbf{D}_{\mathbf{1}}$ ) Mesencephalon: OX-2R/CB1R co-localization in TL, caudal $(\mathrm{Hc})$ and dorsal $(\mathrm{Hd})$ zone of the periventricular hypothalamus, torus lateralis (Tla), central nucleus of inferior lobe (CIL) and diffuse nucleus of inferior lobe (DIL). (E, $\left.\mathbf{E}_{\mathbf{1}}\right)$ Rhombencephalon: OX-2R/CB1R co-localization in TeO, octaval nerve (VIII), intermediate reticular formation (IMRF) and tractus tectobulbaris (TTB). AON, anterior octaval nucleus; Cantd, commissura anterior, pars dorsalis;

(Continued)
FIGURE 1 | Continued

Cce, corpus cerebelli; Chor, Commissura horizontalis; CM, corpus mammillaris; CP, central posterior thalamic nucleus; CPN, central pretectal nucelus; Cpop, commissura postoptica; DAO, dorsal accessory optic nucleus; DiV, Diencephalic ventricle; DOT, dorsomedial optic tract; DP, dorsal posterior thalamic nucleus; DTN, dorsal tegmental nucleus; EG, eminentia granularis; End, entopeduncular nucleus, dorsal part; FR, fasciculus retroflexus; I, intermediate thalamic nucleus; Lca, lobus caudalis cerebelli; LFB, lateral forebrain bundle; LLF, lateral longitudinal fascicle; LOT, lateral olfactory tract; MFB, medial forebrain bundle; MLF, medial longitudinal fascicle; MON, medial octavolateralis nucleus; MOT, medial olfactory tract; PGZ, Periventricular gray zone of the optic tectum; Pit, pituitary; PPd, periventricular pretectal nucleus, dorsal part; PPp, parvocellular preoptic nucleus, posterior part; PPV, periventricular pretectal nucleus, ventral part; PSm, magnocellular superficial pretectal nucleus; PSp, parvocellular superficial pretectal nucleus; SC, suprachiasmatic nucleus; SGT, secondary gustatory tract; TelV, telencephalic ventricle; TeV, Tectal ventricle; TPM, tractus pretectomammillaris; TPp, periventricular nucleus of posterior tuberculum; TS, torus semicircularis; Val, lateral division of valvula cerebelli; VL, Ventrolateral thalamic nucleus; VM, Ventromedial thalamic nucleus; VOT, ventral optic tract; $\mathrm{Vv}$, ventral nucleus of ventral telencephalic area. Scale bar, $250 \mu \mathrm{m}$.

the investigation of the basic and conserved physiological functions controlled by orexins and ECs signaling, highly preserved among the vertebrates. In this study, we therefore employed immunohistochemistry and confocal imaging to define the OX-2R/CB1R receptors anatomical distribution and co-expression in the whole zebrafish brain, as well as the liquid chromatography-atmospheric pressure chemical ionization-mass spectrometry (LC-APCI-MS) to measure the changes of 2-AG levels induced by OX-A, to investigate the regulation of the $2-\mathrm{AG}$ production mediated by $\mathrm{OX}-2 \mathrm{R}$ activation.

\section{MATERIALS AND METHODS}

\section{Animals}

Animals were housed under standard conditions of photoperiod (14:10 LD; ZT0, $9 \mathrm{AM})$ and temperature $\left(28^{\circ} \mathrm{C}\right)$. The current study was carried out in the Aquaculture Lab of the Ferdowsi University of Mashhad (FUM). This project was approved by FUM animal ethics committee. Fish used in this study were treated in accordance with the European Commission recommendation 2007/526/EC and 2010/63/UE on revised guidelines for the accommodation and care of animals used for experimentation and other scientific purposes. All efforts were made to minimize fish suffering. Zebrafish did not receive medical treatment prior or during the experience. No deaths occurred in the facilities before the euthanasia of animals used for the experiments.

\section{Tissue Processing and Immunohistochemistry}

For the immunohistochemistry, 4-month-old females $(n=6)$ and males $(n=6)$ were suppressed in ice water. After skull opening, brains were removed and fixed overnight $4^{\circ} \mathrm{C}$ by immersion in phosphate-buffered saline (PBS; pH 7.4) containing $4 \%$ paraformaldehyde (PFA). The brains were washed in PBS 
TABLE 1 | Co-distribution of OX-2R and CB1R in the zebrafish brain and homologous mammalian brain regions.

\begin{tabular}{|c|c|c|c|}
\hline & $\begin{array}{c}\text { Zebrafish } \\
\text { brain } \\
\text { regions }\end{array}$ & $\begin{array}{c}\text { Mammalian } \\
\text { brain } \\
\text { regions }\end{array}$ & $\begin{array}{c}\text { Overlapping } \\
\text { distributions } \\
\text { of OX-2R } \\
\text { and CB1R }\end{array}$ \\
\hline \multirow[t]{8}{*}{ Telencephalon } & $\mathrm{Vl}$ & Basal ganglia & + \\
\hline & $\mathrm{Vd}$ & Basal ganglia & + \\
\hline & $\mathrm{Dm}$ & Amygdala & + \\
\hline & $\mathrm{Dd}$ & & + \\
\hline & Dc & & + \\
\hline & $\mathrm{DI}$ & Hippocampus & + \\
\hline & $\mathrm{Dp}$ & & + \\
\hline & NT & & + \\
\hline \multirow[t]{11}{*}{ Diencephalon } & VM & & + \\
\hline & $\mathrm{VL}$ & & + \\
\hline & Hav & $\begin{array}{c}\text { Medial habenular } \\
\text { nuclei }\end{array}$ & + \\
\hline & $\mathrm{Had}$ & $\begin{array}{l}\text { Lateral habenular } \\
\text { nuclei }\end{array}$ & + \\
\hline & $\mathrm{CP}$ & & + \\
\hline & $\begin{array}{c}\text { Parvocellular } \\
\text { preoptic } \\
\text { nucleus }\end{array}$ & & + \\
\hline & $\begin{array}{l}\text { Magnocellular } \\
\text { nucleus }\end{array}$ & $\begin{array}{c}\text { Paraventricular } \\
\text { nucleus }\end{array}$ & + \\
\hline & SC & & + \\
\hline & VOT & & + \\
\hline & LFB & & + \\
\hline & $\mathrm{HV}$ & Arcuate nucleus & + \\
\hline $\begin{array}{l}\text { Basal } \\
\text { diencephalon/ }\end{array}$ & PTN & & + \\
\hline \multirow[t]{11}{*}{ Mesencephalon } & PGI & $\begin{array}{c}\text { Sensory thalamic } \\
\text { nuclei }\end{array}$ & + \\
\hline & PGm & $\begin{array}{c}\text { Sensory thalamic } \\
\text { nuclei }\end{array}$ & + \\
\hline & $\mathrm{LH}$ & & + \\
\hline & $\mathrm{Hd}$ & & + \\
\hline & $\mathrm{Hc}$ & & + \\
\hline & TLa & & + \\
\hline & DIL & & + \\
\hline & $\mathrm{TeO}$ & $\begin{array}{l}\text { Visual cortex or } \\
\text { superior colliculus }\end{array}$ & + \\
\hline & $\mathrm{TeV}$ & & + \\
\hline & $\mathrm{TL}$ & & + \\
\hline & ТТВ & & + \\
\hline \multirow[t]{3}{*}{ Rhombencephalon } & $\begin{array}{c}\text { Medulla } \\
\text { oblongata }\end{array}$ & Medulla oblongata & \\
\hline & IMRF & Reticular formation & + \\
\hline & VIII & & + \\
\hline
\end{tabular}

and transferred to $20 \%$ sucrose overnight $(\mathrm{ON})$, followed by $30 \%$ sucrose in $0.1 \mathrm{M}$ PBS $\mathrm{ON}$ at $4^{\circ} \mathrm{C}$. The brains were frozen and embedded in a Frozen Section Media (Leica Biosystems), cryosectioned with a Leica CM3050S cryostat into $12 \mu \mathrm{m}$-thick serial sections in the coronal plane, collected in alternate series and processed for immunofluorescence. The sections were washed with $0.25 \%$ Triton $\mathrm{X}-100$ in PBS, pH 7.4 (PBS-T), and incubated for $12 \mathrm{~h}$ at room temperature with primary antibodies diluted in PBS-T. The following primary antibodies were used: goat antibody against OX-2R diluted 1:200 (code sc-8074; Santa Cruz Biotechnology, Santa Cruz, CA, USA), rabbit antibody against CB1R diluted
1:200 (code ab23703; Abcam, Cambridge, UK). After the incubation with the primary antibodies, the sections were washed several times in PBS-T and incubated for $2 \mathrm{~h}$ at room temperature with donkey anti rabbit Alexa 488- and donkey anti goat Alexa 594-conjugated secondary antibodies (1:100; Invitrogen, ThermoFisher Scientific, France). Tissue sections were washed in PBS and finally counterstained with DAPI (4',6diamidino-2-phenylindole; Sigma-Aldrich S.r.l., Milan, Italy). All slides were coverslipped with Aquatex mounting medium (Merck, Darmstadt, Germany). The immunostained sections were observed with a confocal microscopy Nikon Eclipse Ti2 (Nikon, Florence, Italy) equipped with $x-y-z$ motorized stage, a digital camera DS-Qi2 (Nikon, Florence, Italy) and the acquisition and Image analysis software NIS-Elements C (Nikon, Florence, Italy). Digital images were acquired using the 5-20-40 $\times$ objectives. We collected serial Z-stacks of images throughout the area of interest (6-10 planes with an increment varying $0.5-1 \mu \mathrm{m}$ ). Images were deconvolved using the imaging deconvolution software by application of ten iterations. Serial $\mathrm{Z}$ planes images were collapsed into a single maximum projection image. Micrographs were saved in TIFF format and adjusted for light and contrast before being assembled on plates using Adobe Photoshop 6.01 (Adobe Systems, San Jose, CA, USA).

\section{Controls}

The specificity of the antibodies was validated with controls that included: (1) omission of primary or secondary antibody staining; (2) pre-absorptions of each primary antibody with an excess of the relative peptide (OX-2R peptide, Santa Cruz; CB1R peptide, Abcam; $100 \mathrm{mg}$ of peptide/ml of diluted antiserum). Internal reaction controls were carried out by substituting primary antisera or secondary antisera with PBS or normal serum in the specific step. A further control of CB1R antibody was done by aligning the epitope sequence and the aminoacid sequence of the protein (Accession: NP_997985.1 GI: 47086397). For OX$2 \mathrm{R}$, we aligned the aminoacids sequences of Homo sapiens and Danio rerio (Accession: ABO61386.1 GI: 134142085) because the epitope was not available. Alignments were done by using Multiple Sequence Alignment.

\section{Protein Extraction and Western Blotting}

Four months of female $(n=3)$ and male $(n=3)$ zebrafish brain were frozen and homogenized in buffer (consisting of $50 \mathrm{mM}$ Tris- $\mathrm{HCl}, \mathrm{pH} 7.0,150 \mathrm{mM} \mathrm{NaCl}, 2 \%$ Triton, $5 \mathrm{mM}$ EDTA, $10 \mathrm{mg} / \mathrm{ml}$ leupeptin, $0.1 \mathrm{U} / \mathrm{ml}$ aprotinin, $1 \mathrm{mM}$ PMSF) using an Ultra-Turrax homogenizer and centrifuged at $16,000 \mathrm{~g}$ for $20 \mathrm{~min}$ at $4^{\circ} \mathrm{C}$. Aliquots of supernatant were subjected to SDS-PAGE analysis using $4 \%$ to $12 \%$ Bis-Trisgels (NuPAGE, Invitrogen). After separation, the proteins were electrophoretically transferred to nitrocellulose membrane with the iBlot transfer system (Invitrogen). Then the membranes were blocked in TBS-T buffer $(150 \mathrm{mM} \mathrm{NaCl}, 20 \mathrm{mM}$ Tris $\mathrm{HCl}$ $\mathrm{pH}$ 7.4, 0.1\% Tween-20) containing $5 \mathrm{~g} 100 \mathrm{~mL}-1$ milk for $1 \mathrm{~h}$ at room temperature. The blots were then incubated $\mathrm{ON}$ with primary antibody anti-OX-2R (code sc-8074; Santa Cruz Biotechnology Inc., Santa Cruz, CA USA) produced in goat, 


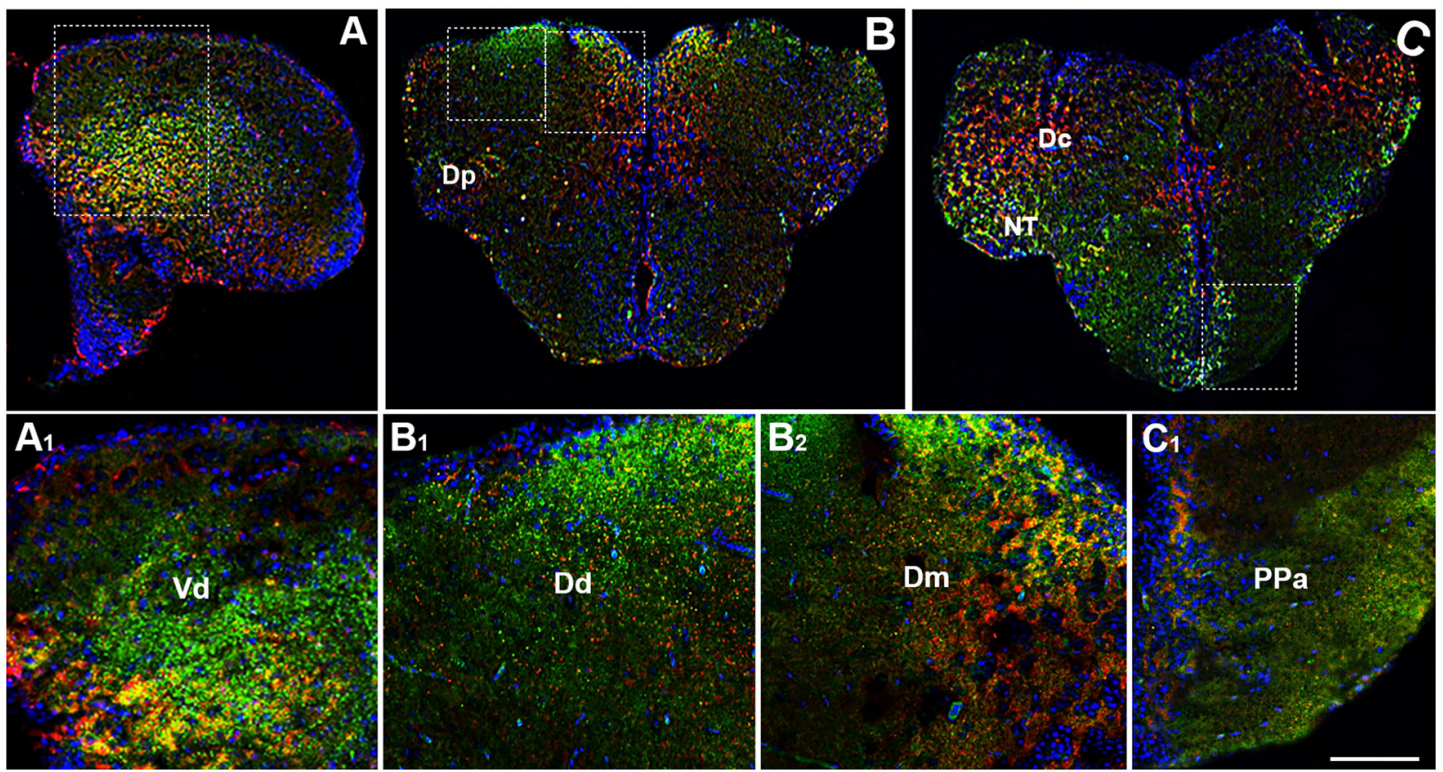

FIGURE 2 | Distribution of OX-2R (red) and CB1R (green), and their co-localization OX-2R/CB1R (yellow) in coronal sections of the telencephalon. (A-C) OX-2R/CB1R co-expression has been observed in the dorsal and ventral telencephalon of zebrafish brain. ( $\left.\mathbf{A}_{\mathbf{1}}\right)$ Higher magnification of the field boxed in (A) showing the OX-2R/CB1R co-expression within the dorsal nucleus of the ventral telencephalon $(\mathrm{Vd})$. $\left(\mathbf{B}_{1}, \mathbf{B}_{2}\right)$ Higher magnification of the fields boxed in $(\mathbf{B})$ showing the OX-2R/CB1R co-expression within the dorsal (Dd) $\left.\mathbf{( B}_{\mathbf{1}}\right)$ and medial (Dm) $\left(\mathbf{B}_{\mathbf{2}}\right)$ part of the dorsal telencephalon. $\left(\mathbf{C}_{\mathbf{1}}\right)$ Higher magnification of the field boxed in $\mathbf{( C )}$ showing the OX-2R/CB1R co-expression within the parvocellular preoptic nucleus, anterior part (Ppa). DAPI (Blue) was used as a counterstaining to show nuclei. Dc, central part of the dorsal telencephalon; Dp, posterior part of the dorsal telencephalon; NT, nucleus taeniae. Scale bar, $250 \mu \mathrm{m}$ for $(\mathbf{A}-\mathbf{C}) ; 50 \mu \mathrm{m}$ for $\left(\mathbf{A}_{\mathbf{1}}, \mathbf{B}_{\mathbf{1}}, \mathbf{B}_{\mathbf{2}}, \mathbf{C}_{\mathbf{1}}\right)$.

diluted 1:500, or anti-CB1R (code ab23703; Abcam, Cambridge, $\mathrm{UK}$ ) produced in rabbit, diluted 1:100, in TBS-T and containing 2.5\% milk. After three washes in TBS-T, the membranes were incubated in TBS-T for $1 \mathrm{~h}$ with secondary antibody, horseradish peroxidase conjugated anti-goat (code 305-035-003; 1:1000, Immuno Research) for OX-2R and anti-rabbit (code sc-2004; 1:10,000; Santa Cruz Biotechnology Inc., Santa Cruz, CA USA) for CB1R, respectively. Proteins were visualized with the ECL Advanced Western blotting detection kit (Amersham) on C-Digit System. Homogenate of mouse hypothalamus was employed as positive control.

\section{Pharmacological Treatment}

The animals ( $n=3$ per group) were treated with intraperitoneal (i.p.) or intracerebroventricular (i.c.v.) injection of $\mathrm{OX}-\mathrm{A}$ (TOCRIS, Bristol, United Kingdom) at the dose of $3 \mathrm{pmol} / \mathrm{g}$ or $0.3 \mathrm{pmol} / \mathrm{g}$, respectively (Yokobori et al., 2011). For i.p. and i.c.v. injection, the effective dose of OX-A and SB334867 was obtained by a dose-response curve. For OX-A doses were 0.3, 3 and $30 \mathrm{pmol} / \mathrm{g}$; for SB334867 0.1, 1 and $10 \mathrm{pmol} / \mathrm{g}$. Another group of animals ( $n=3$ per group) was pretreated with i.p. or i.c.v. injection of orexin receptor antagonist SB334867 (10 pmol/g; TOCRIS, Bristol, United Kingdom) followed by OX-A i.p. injection 30 min later or i.c.v. injection 15 min later. SB334867 has been reported to be able to antagonize orexin at the fish orexin receptor (Miura et al., 2007; Yokobori et al., 2011). The treatment was performed at 9-11 AM to avoid any possible circadian variability. The skull was opened and zebrafish brains were rapidly removed after $3 \mathrm{~h}$ of i.p and $1 \mathrm{~h}$ of i.c.v. treatment. ICV administration was carried out as described previously (Yokobori et al., 2011).

\section{Lipid Extraction and Measurement of Endocannabinoid Levels in the Brain}

Each single brain was homogenized in 5 volume chloroform/methanol/ Tris. $\mathrm{HCl}$ (50 mmol L-1, pH 7.5; 2:1:1, volume-to-volume ratio) containing $10 \mathrm{pmol}$ of $[\mathrm{H}]_{8}$-Anandamide $\left([\mathrm{H}]_{8}\right.$-AEA $)$ and 50 pmol of $[\mathrm{H}]_{5}-2$ arachidonoylglycerol $\left([\mathrm{H}]_{5}-2-\mathrm{AG}\right)$ as internal standards. Homogenates were centrifuged at $13,000 \times g$ for $16 \min \left(4^{\circ} \mathrm{C}\right)$, the aqueous phase plus debris was collected and extracted four times with 1 volume chloroform. The lipid-containing organic phases were dried down, weighed and pre-purified by open-bed chromatography on silica columns eluted with increasing concentrations of methanol in chloroform. Fractions for 2-AG and AEA measurement were obtained by eluting the columns with 9:1 (by volume) chloroform/methanol and then analyzed by liquid chromatography-atmospheric pressure chemical ionization-mass spectrometry (LCAPCI-MS), by using a Shimadzu high-performance liquid chromatography apparatus (LC-10ADVP) coupled to a Shimadzu quadruple mass spectrometer (LCMS-2020) via a Shimadzu atmospheric pressure chemical ionization interface. LC-APCI-MS analyses were carried out in the selected ion monitoring mode, using $\mathrm{m} / \mathrm{z}$ values of 384.35 and 379.35 (molecular ions +1 for deuterated and undeuterated 2-AG), 

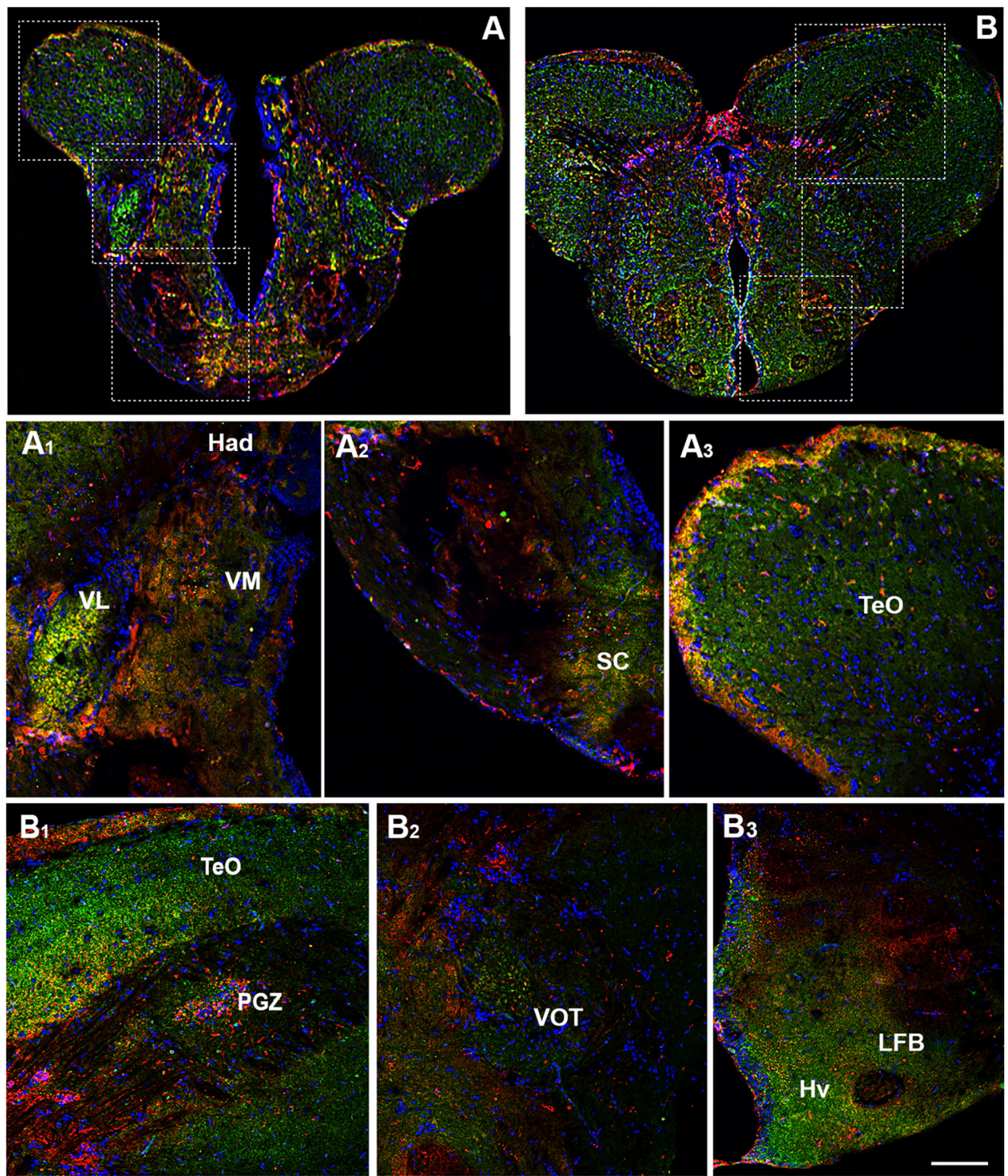

FIGURE 3 | Distribution of OX-2R (red) and CB1R (green), and their co-localization OX-2R/CB1R (yellow) in coronal sections of the diencephalon. (A,B) OX-2R/CB1R co-expression has been observed in the suprachiasmatic nucleus (SC), ventrolateral (VL) and ventromedial (VM) thalamic nuclei, dorsal habenular nucleus ( $\mathrm{Had})$, optic tectum (TeO), periventricular gray zone of the optic tectum (PGZ), ventral optic tract (VOT), lateral forebrain bundle ( $\mathrm{LFB}$ ) and ventral zone of the periventricular hypothalamus $(\mathrm{Hv})$. $\left(\mathbf{A}_{\mathbf{1}}-\mathbf{A}_{\mathbf{3}}\right)$ Higher magnification of the fields boxed in $(\mathbf{A})$ showing the OX-2R/CB1R co-expression within the Had, VL, VM $\left(\mathbf{A}_{\mathbf{1}}\right)$, SC

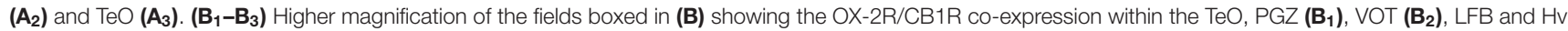
$\left.\mathbf{( B}_{\mathbf{3}}\right)$. DAPI (Blue) was used as a counterstaining to show nuclei. Scale bar, $250 \mu \mathrm{m}$ for $(\mathbf{A}, \mathbf{B}) ; 50 \mu \mathrm{m}$ for $\left(\mathbf{A}_{\mathbf{1}}-\mathbf{A}_{\mathbf{3}}, \mathbf{B}_{\mathbf{1}}-\mathbf{B}_{\mathbf{3}}\right)$.

356 and 348 (molecular ions +1 for deuterated and undeuterated AEA). The amounts of analyses in tissues quantified by isotope dilution with the above mentioned deuterated standards were expressed as picomoles per milligram of lipid extract.

\section{Statistical Analyses}

The data are expressed as mean \pm SEM and were analyzed with GraphPad Prism six software, version 6.05 (GraphPad Inc.). Statistical differences among groups were determined by one-way ANOVA followed by post hoc Tukey test for comparison among means. $p<0.05$ was considered statistically significant.

\section{RESULTS}

\section{OX-2R and CB1R Co-expression in the Adult Brain}

The analysis of OX-2R/CB1R colocalization was carried out in the whole brain of adult zebrafish. The anatomical 


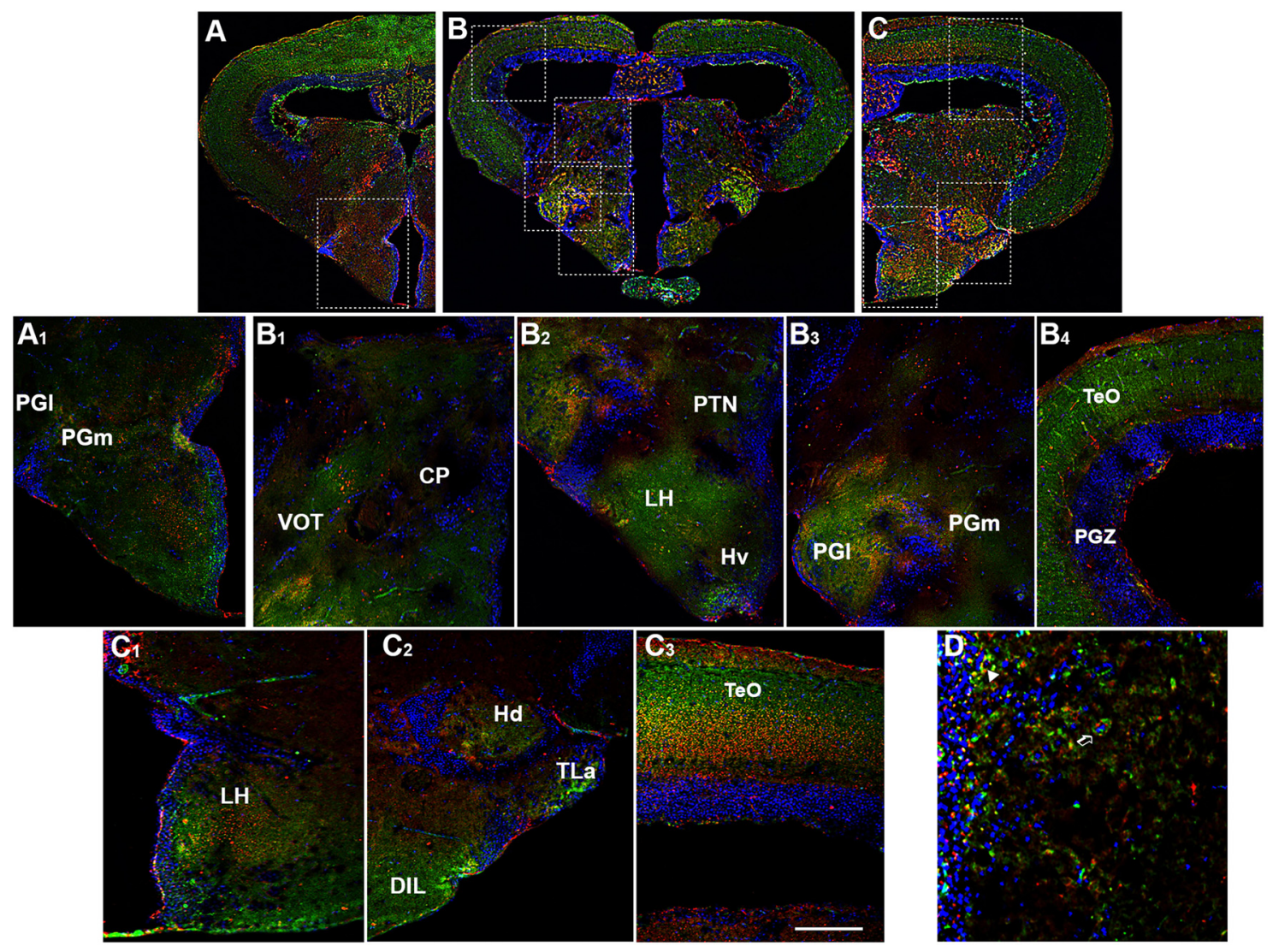

FIGURE 4 | Distribution of OX-2R (red) and CB1R (green), and their co-localization OX-2R/CB1R (yellow) in coronal sections of the diencephalon/midbrain. (A-C) OX-2R/CB1R co-expression has been observed in the lateral (PGI) and medial (PGm) preglomerular nuclei, VOT, central posterior thalamic nucleus (CP), posterior tuberal nucleus (PTN), lateral hypothalamus (LH), ventral zone of the periventricular hypothalamus (Hv), periventricular gray zone of the optic tectum (PGZ), optic

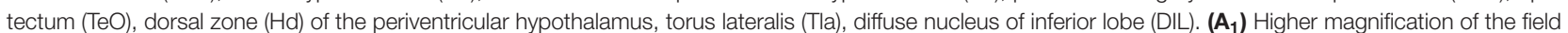
boxed in (A) showing the OX-2R/CB1R co-expression within the PGl and PGm. $\left(\mathbf{B}_{\mathbf{1}}-\mathbf{B}_{\mathbf{4}}\right)$ Higher magnification of the fields boxed in (B) showing the OX-2R/CB1R

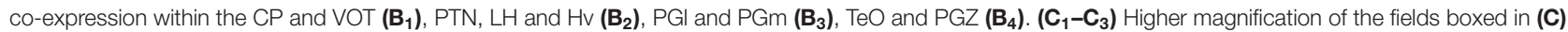

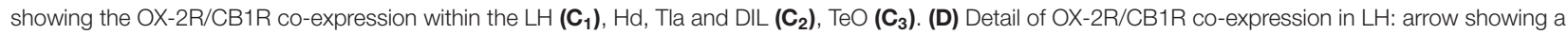
putative adjacent localization of OX-2R/CB1R and arrowhead showing a putative co-localization and overlapping of OX-2R/CB1R in the same cells. DAPI (Blue) was used as a counterstaining to show nuclei. Scale bar, $250 \mu \mathrm{m}$ for $(\mathbf{A}-\mathbf{C}) ; 50 \mu \mathrm{m}$ for $\left(\mathbf{A}_{1}, \mathbf{B}_{1}-\mathbf{B}_{\mathbf{4}}, \mathbf{C}_{\mathbf{1}}-\mathbf{C}_{\mathbf{3}}\right) ; 25 \mu \mathrm{m}$ for (D).

description and the nomenclature follow the atlas by Wullimann et al. (1996). An overview of the co-distribution and co-expression of OX-2R and CB1R is presented in the scheme in Figure 1 and Table 1.

The specificity of both OX-2R and CB1 in the zebrafish brain was evaluated by Western blotting (Supplementary Figure S1) and phylogenetic analyses (Supplementary Figure S2) to confirm the degree of conservation. In zebrafish, as in the mouse hypothalamus (used as positive control), the polyclonal antibody against OX-2R showed one band of approximately $38 \mathrm{kDa}$ (OX-2R) and that against CB1R of about $60 \mathrm{kDa}$, according to what has also been reported in the datasheet of the antibodies (Supplementary Figure S1) and by previous studies on fish (D'Angelo et al., 2016a). In addition, sequences alignment confirmed that zebrafish OX-2R aminoacid sequence share a $72.6 \%$ of identity with human (412 aminoacid residues overlap) and the epitope of the
CB1R antibody revealed a degree of conservation of $75 \%$, being 9 out of 12 conserved aminoacids (Supplementary Figure S2).

\section{Telencephalon}

By using immunohistochemistry, we found a co-expression of $\mathrm{OX}-2 \mathrm{R}$ and $\mathrm{CB} 1 \mathrm{R}$ in several telencephalic structures. In the brain of adult zebrafish, the telencephalon includes two major subdivisions: the dorsal telencephalon (pallium) and ventral telencephalon (subpallium). Dorsal and ventral telencephalon can be further divided into minor fields depending on the cytoarchitecture and fiber connections (Nieuwenhuys, 2009; Ganz et al., 2014). OX-2R/CB1R co-staining was observed in the lateral nucleus (Vl) and dorsal nucleus $(\mathrm{Vd})$ of the ventral telencephalic area (Figures $\mathbf{2} \mathbf{A}, \mathbf{A}_{\mathbf{1}}$ ) and in the whole dorsal telencephalic area (D; Figure 1), i.e., in the medial (Dm), dorsal $(\mathrm{Dd})$, central $(\mathrm{Dc})$, lateral $(\mathrm{Dl})$ and posterior $(\mathrm{Dp})$ part of the dorsal telencephalic area (Figures $\mathbf{2} \mathbf{B}, \mathbf{B}_{1}, \mathbf{B}_{2}, \mathbf{C}, \mathbf{C}_{\mathbf{1}}$ ). Moreover, 

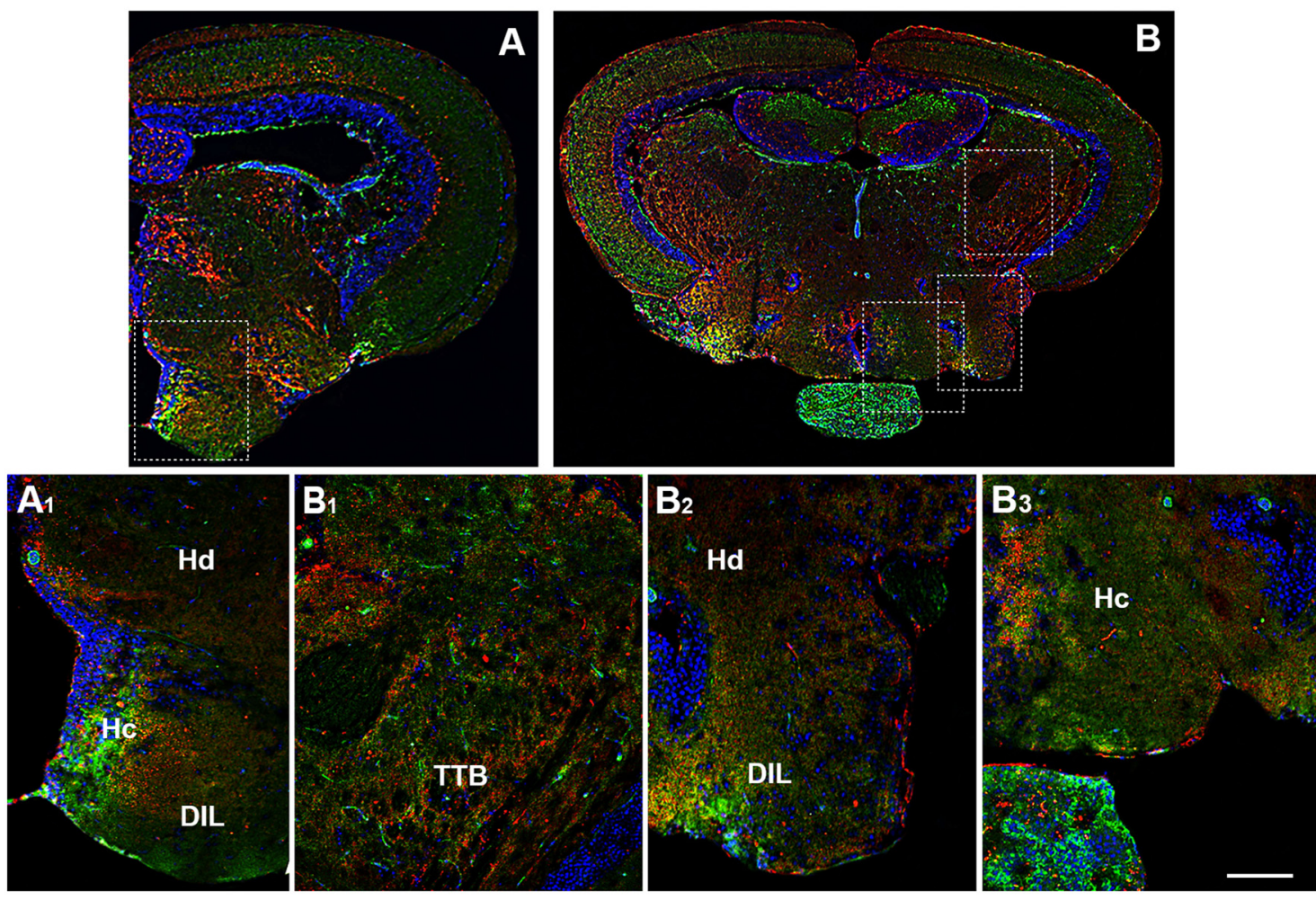

FIGURE 5 | Distribution of OX-2R (red) and CB1R (green), and their co-localization OX-2R/CB1R (yellow) in coronal sections of diencephalon/mesencephalon. (A,B) OX-2R/CB1R co-expression has been observed in the dorsal $(\mathrm{Hd})$ and central $(\mathrm{Hc})$ zone of the periventricular hypothalamus, DIL and TTB. $\left(\mathbf{A}_{\mathbf{1}}\right) \mathrm{Higher}$ magnification

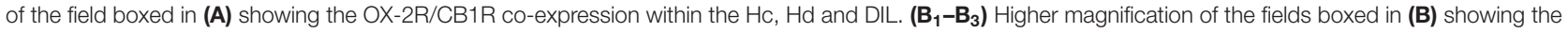

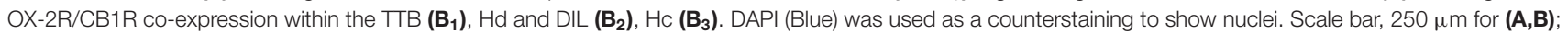
$50 \mu \mathrm{m}$ for $\left(\mathbf{A}_{1}, \mathbf{B}_{1}-\mathbf{B}_{3}\right)$.

OX-2R/CB1R co-localization was found in the nucleus taeniae (NT) and in close contact with the telencephalic ventricle in the parvocellular preoptic nucleus, anterior part (Ppa; Figures 2C, $\mathrm{C}_{1}$ ).

\section{Diencephalon}

The immunohistochemical analysis of adult zebrafish diencephalon showed OX-2R/CB1R co-localization also in this zebrafish brain region. This brain region comprises the prethalamus, habenula and thalamus, which are brain areas highly conserved across vertebrates (Stephenson-Jones et al., 2011; Cheng et al., 2014).

The prethalamus includes the VM and the ventrolateral (VL) thalamic nuclei which are present in zebrafish, but not in the mammalian brain (Mueller, 2012). Both nuclei showed the OX-2R/CB1R co-expression (Figures $\mathbf{3 A}, \mathbf{A}_{\mathbf{1}}$ ). The habenula includes the ventral (Hav) and dorsal (Had) habenular nuclei and the OX-2R/CB1R co-expression was found mainly in the Had (Figures $\mathbf{3 A}, \mathbf{A}_{\mathbf{1}}$ ). The thalamus is subdivided into the anterior thalamic nucleus, the dorsal posterior thalamic nucleus and the central posterior thalamic nucleus (CP). The thalamus, in particular the $\mathrm{CP}$, showed $\mathrm{OX}-2 \mathrm{R} / \mathrm{CB} 1 \mathrm{R}$ co-expression (Figures $4 \mathrm{~B}, \mathrm{~B}_{1}$ ).
Another main area of the diencephalon is the preoptic area (PO) which includes different subnuclei, such as the anterior and posterior parvocellular and the magnocellular preoptic nuclei, and the suprachiasmatic nucleus (SC; Braford and Northcutt, 1983; Wullimann et al., 1996; Rupp and Northcutt, 1998; Filippi et al., 2010; Yamamoto et al., 2010, 2011). All of these diencephalic nuclei showed OX-2R/CB1R co-localization (Figures 3A, $\mathbf{A}_{2}$ ).

Moving caudally along the diencephalon, other three regions were characterized by the $\mathrm{OX}-2 \mathrm{R} / \mathrm{CB} 1 \mathrm{R}$ co-expression: the ventral optic tract (VOT; Figures $\mathbf{3} \mathbf{B}, \mathbf{B}_{2}, \mathbf{4} \mathbf{B}, \mathbf{B}_{\mathbf{1}}$ ), the lateral forebrain bundle (LFB; Figures $\mathbf{3} \mathbf{B}, \mathbf{B}_{\mathbf{3}}$ ) and the ventral zone of the periventricular hypothalamus (Hv; Figures $3 B, B_{3}, 4 B, B_{2}$ ).

\section{Basal Diencephalon/Mesencephalon}

The basal diencephalon of zebrafish comprises the posterior tuberculum and the preglomerular complex. The posterior tuberculum includes all the nuclei intercalated between prethalamus and hypothalamus, such as periventricular nucleus of the posterior tuberculum, paraventricular organ and posterior tuberal nucleus (PTN; Rupp et al., 1996; Wullimann et al., 1996; Herget et al., 2014). The preglomerular complex is divided in anterior, 

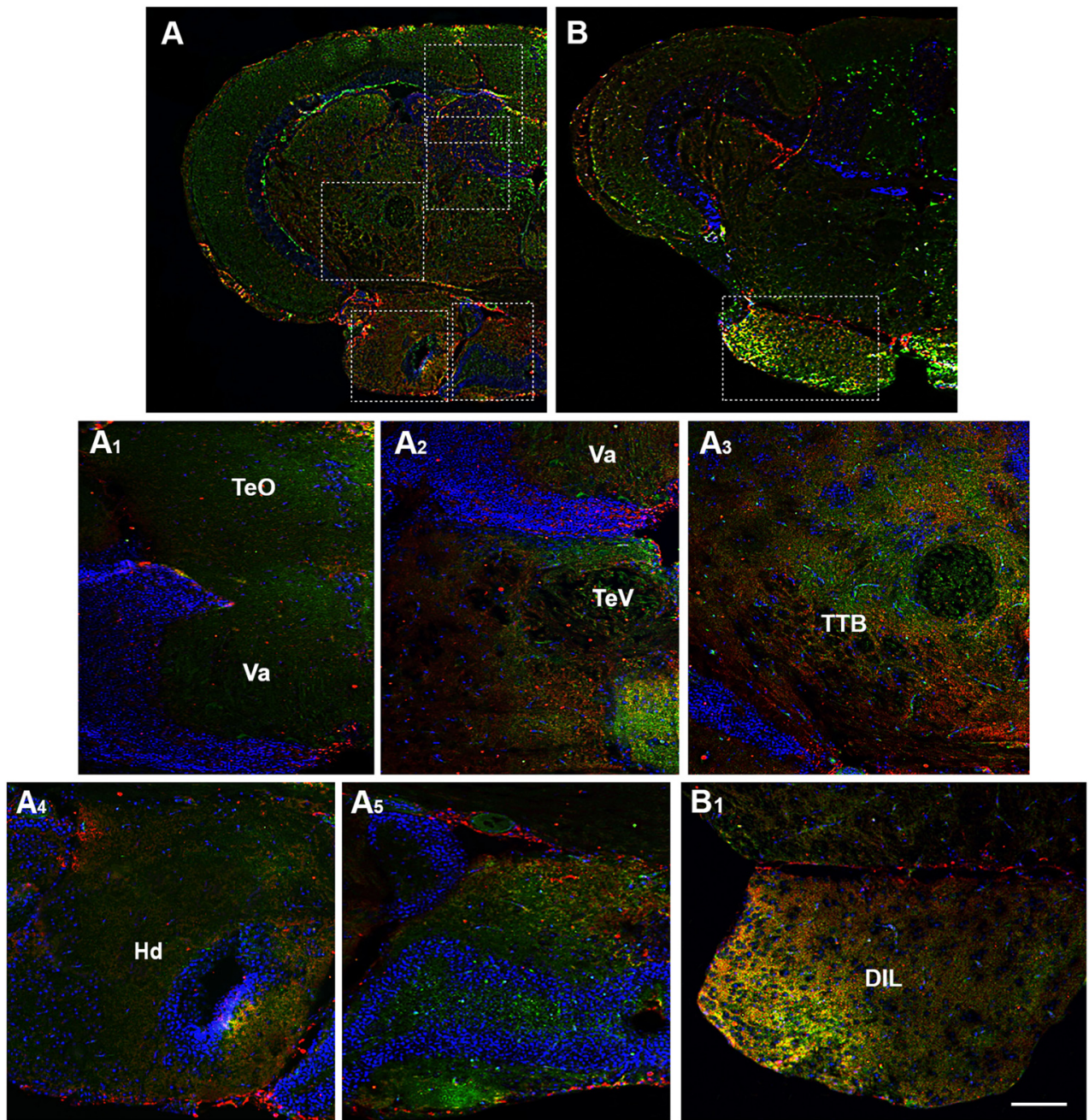

FIGURE 6 | Distribution of OX-2R (red) and CB1R (green), and their co-localization OX-2R/CB1R (yellow) in coronal sections of the midbrain. (A,B) OX-2R/CB1R co-expression has been observed in the optic tectum (TeO), along the tectal ventricle (TeV), TTB, dorsal ( $\mathrm{Hd})$ and central ( $\mathrm{Hc}$ ) zone of the periventricular

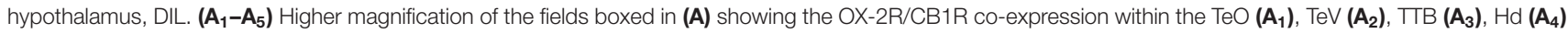
$\mathrm{Hc}\left(\mathbf{A}_{5}\right)$. $\left(\mathbf{B}_{1}\right)$ Higher magnification of the field boxed in $\mathbf{( B )}$ showing the OX-2R/CB1R co-expression within the DIL. DAPI (Blue) was used as a counterstaining to show nuclei. Va, Valvula Cerebelli. Scale bar, $250 \mu \mathrm{m}$ for $(\mathbf{A}, \mathbf{B}) ; 50 \mu \mathrm{m}$ for $\left(\mathbf{A}_{\mathbf{1}}-\mathbf{A}_{\mathbf{5}}, \mathbf{B}_{\mathbf{1}}\right)$.

lateral, medial and caudal preglomerular nuclei (Pga, PGl, PGm, PGc). The OX-2R/CB1R co-expression was detected in the PTN (Figures $\mathbf{4} \mathbf{B}, \mathbf{B}_{2}$ ), PGl and PGm (Figures $4 \mathrm{~A}, \mathrm{~A}_{1}, \mathrm{~B}, \mathrm{~B}_{3}$ ).

By morphological analysis, OX-2R/CB1R co-localization was found mainly in the following hypothalamic region: LH (Figures $4 \mathbf{B}, \mathbf{B}_{2}, \mathbf{C}, \mathrm{C}_{1}, \mathbf{D}$ ), dorsal ( $\mathrm{Hd}$; Figures $\mathbf{4 C}, \mathbf{C}_{2}$, $\left.\mathbf{5} \mathbf{A}, \mathbf{A}_{1}, \mathbf{B}, \mathbf{B}_{2}, \mathbf{6} \mathbf{A}, \mathbf{A}_{4}\right)$ and caudal $(\mathrm{Hc})$ zone of periventricular hypothalamus (Figures $\mathbf{5} \mathbf{A}, \mathbf{A}_{1}, \mathbf{B}, \mathbf{B}_{3}, \quad \mathbf{6} \mathbf{A}, \mathbf{A}_{5}$ ), torus lateralis (Tla; Figures $\mathbf{4} \mathbf{C}, \mathbf{C}_{2}$ ) and diffuse nucleus of inferior lobe (DIL; Figures $4 \mathrm{C}, \mathrm{C}_{2}, \quad \mathbf{5 A}, \mathrm{A}_{1}, \mathbf{B}, \mathrm{B}_{2}$, $\left.6 \mathrm{~B}, \mathrm{~B}_{1}\right)$.

Moving caudally towards the midbrain, prominent structure is the optic tectum ( $\mathrm{TeO})$. Immunohistochemical studies evidenced $\mathrm{OX}-2 \mathrm{R} / \mathrm{CB} 1 \mathrm{R}$ co-staining in the PGZ of the $\mathrm{TeO}$ (Figures $\mathbf{3} \mathbf{B}, \mathbf{B}_{\mathbf{1}}, \mathbf{4} \mathbf{B}, \mathbf{B}_{\mathbf{1}}$ ) and in the central and more external layers of the TeO (Figures $\mathbf{3} A, \mathbf{A}_{3}, \mathbf{B}, \mathbf{B}_{\mathbf{1}}$, $\left.\mathbf{4 B}, \mathbf{B}_{4}, \mathbf{C}, \mathbf{C}_{3}, \mathbf{6 A}, \mathbf{A}_{1}\right)$, but also around the tectal ventricle $(\mathrm{TeV}$; Figures $6 \mathrm{~A}, \mathrm{~A}_{2}$ ) and in the TL (Figure 4 ), which is a conspicuous paired structure of the midbrain connecting the bilateral tectal lobes. Moreover, the morphological analysis showed $\mathrm{OX}-2 \mathrm{R} / \mathrm{CB} 1 \mathrm{R}$ co-expression in the midbrain tegmentum, particularly in the tractus tectobulbaris (TTB; Figures $\mathbf{5 B}, \mathbf{B}_{\mathbf{1}}$, 6A, $\left.\mathrm{A}_{3}\right)$.

\section{Rhombencephalon}

The rhombencephalon is composed of the medulla oblongata, the ventral anterior Pons and the dorso anterior cerebellum (CC) and contributes to several pairs of cranial nerves, such as the octaval nerve (VIII). In the rhombencephalon a corporation of cell groups forms the reticular formation. By immunohistochemical analysis, OX-2R/CB1R co-distribution 

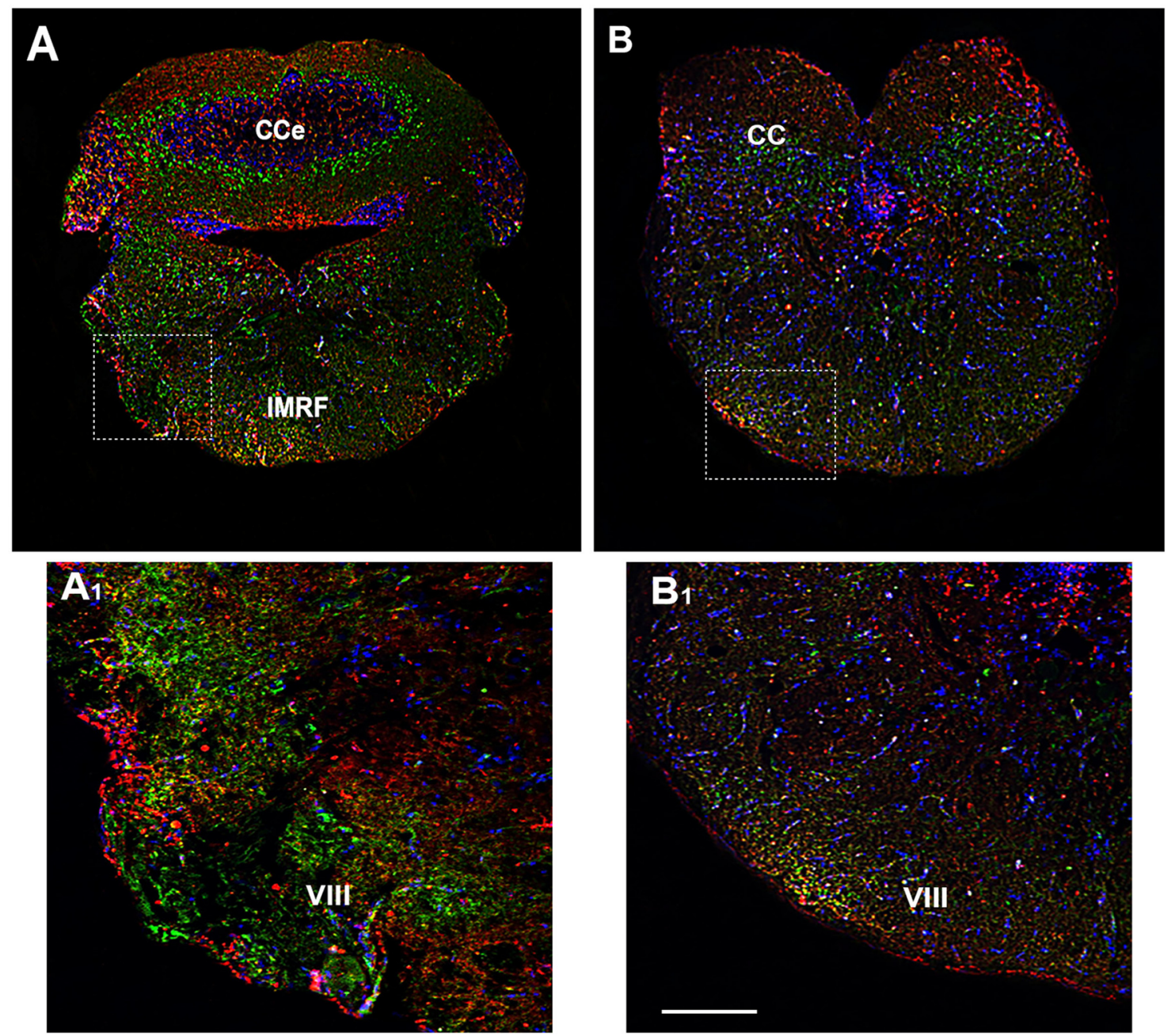

FIGURE 7 | Distribution of OX-2R (red) and CB1R (green), and their co-localization OX-2R/CB1R (yellow) in coronal sections of the rhombencephalon. (A,B) OX-2R/CB1R co-expression has been observed in the IMRF and octaval nerve (VIII). $\left(\mathbf{A}_{1}, \mathbf{B}_{1}\right)$ Higher magnification of the fields boxed in $(\mathbf{A}, \mathbf{B})$ showing the OX-2R/CB1R co-expression in the VIII. DAPI (Blue) was used as a counterstaining to show nuclei. Cce, corpus cerebelli. Scale bar, $250 \mu \mathrm{m}$ for (A,B); $50 \mu \mathrm{m}$ for $\left(A_{1}, B_{1}\right)$

was observed in the medulla oblongata, in the intermediate reticular formation (IMRF) and in VIII (Figures $\mathbf{7 A}, \mathbf{A}_{\mathbf{1}}, \mathbf{B}, \mathbf{B}_{\mathbf{1}}$ ).

\section{OX-2R and CB1R Functional Interaction}

Several studies have demonstrated that synthetic human OX-A has effective physiological activity in zebrafish and goldfish (Volkoff et al., 1999, 2003; Volkoff and Peter, 2000, 2001; Nakamachi et al., 2006; Yokogawa et al., 2007). A dose-response curve was performed to define the i.p. injected OX-A (OX-A 0.3 pmol/g: $9.8 \pm 3.6 \mathrm{pmol} / \mathrm{mg}$, OX-A 3 pmol/g: $28.3 \pm 2.2 \mathrm{pmol} / \mathrm{mg}$, OX-A $30 \mathrm{pmol} / \mathrm{g}$ $22.1 \pm 2.9 \mathrm{pmol} / \mathrm{mg}$ ), i.c.v. injected OX-A (OX-A $0.03 \mathrm{pmol} / \mathrm{g}$ : $12.1 \pm 3.3 \mathrm{pmol} / \mathrm{mg}$, OX-A $0.3 \mathrm{pmol} / \mathrm{g}: 33.2 \pm 3.5 \mathrm{pmol} / \mathrm{mg}$, OX-A $3 \mathrm{pmol} / \mathrm{g}: 29.3 \pm 2.9 \mathrm{pmol} / \mathrm{mg}$ ) and SB334867 (OXA $3 \mathrm{pmol} / \mathrm{g}+$ SB334867 $0.1 \mathrm{pmol} / \mathrm{g}: 26.4 \pm 2.8 \mathrm{pmol} / \mathrm{mg}$,
OX-A $3 \mathrm{pmol} / \mathrm{g}+$ SB334867 $1 \mathrm{pmol} / \mathrm{g}: 24.3 \pm 3.1 \mathrm{pmol} / \mathrm{mg}$, OX-A $3 \mathrm{pmol} / \mathrm{g}+\mathrm{SB} 33486710 \mathrm{pmol} / \mathrm{g} ; 11.6 \pm 2.5 \mathrm{pmol} / \mathrm{mg}$ ) effective dose. As shown in the Figure 8, 2-AG levels, detected using LC-APCI-MS, were significantly increased in zebrafish after i.p or i.c.v. injection with OX-A (i.p.: ctrl $12.6 \pm 2 \mathrm{pmol} / \mathrm{mg}$ vs. OX-A $25.1 \pm 0.6 \mathrm{pmol} / \mathrm{mg}$; i.c.v.: ctrl $10.9 \pm 0.5 \mathrm{pmol} / \mathrm{mg}$ vs. OX-A $31.5 \pm 5.3 \mathrm{pmol} / \mathrm{mg}$ ), and this elevation was prevented by $30 \mathrm{~min}$ of pretreatment with the orexin receptor antagonist, SB334867 (i.p.: OX-A $25.1 \pm 0.6 \mathrm{pmol} / \mathrm{mg}$ vs. SB334867 + OX-A $15.5 \pm 3 \mathrm{pmol} / \mathrm{mg}$; i.c.v.: OX-A $31.5 \pm 5.3 \mathrm{pmol} / \mathrm{mg}$ vs. SB334867 + OX-A $11.8 \pm 3.2 \mathrm{pmol} / \mathrm{mg}$ ). No significative differences were found for the AEA (i.p.: ctrl $0.9 \pm 0.2 \mathrm{pmol} / \mathrm{mg}$, OX-A $0.7 \pm 0.2 \mathrm{pmol} / \mathrm{mg}$, SB334867 + OX-A $0.8 \pm 0.4 \mathrm{pmol} / \mathrm{mg}$; i.c.v.: ctrl $0.7 \pm 0.1 \mathrm{pmol} / \mathrm{mg}$, OX-A $0.5 \pm 0.2 \mathrm{pmol} / \mathrm{mg}, \mathrm{SB} 334867+$ OX-A $0.9 \pm 0.2 \mathrm{pmol} / \mathrm{mg}$ ). 

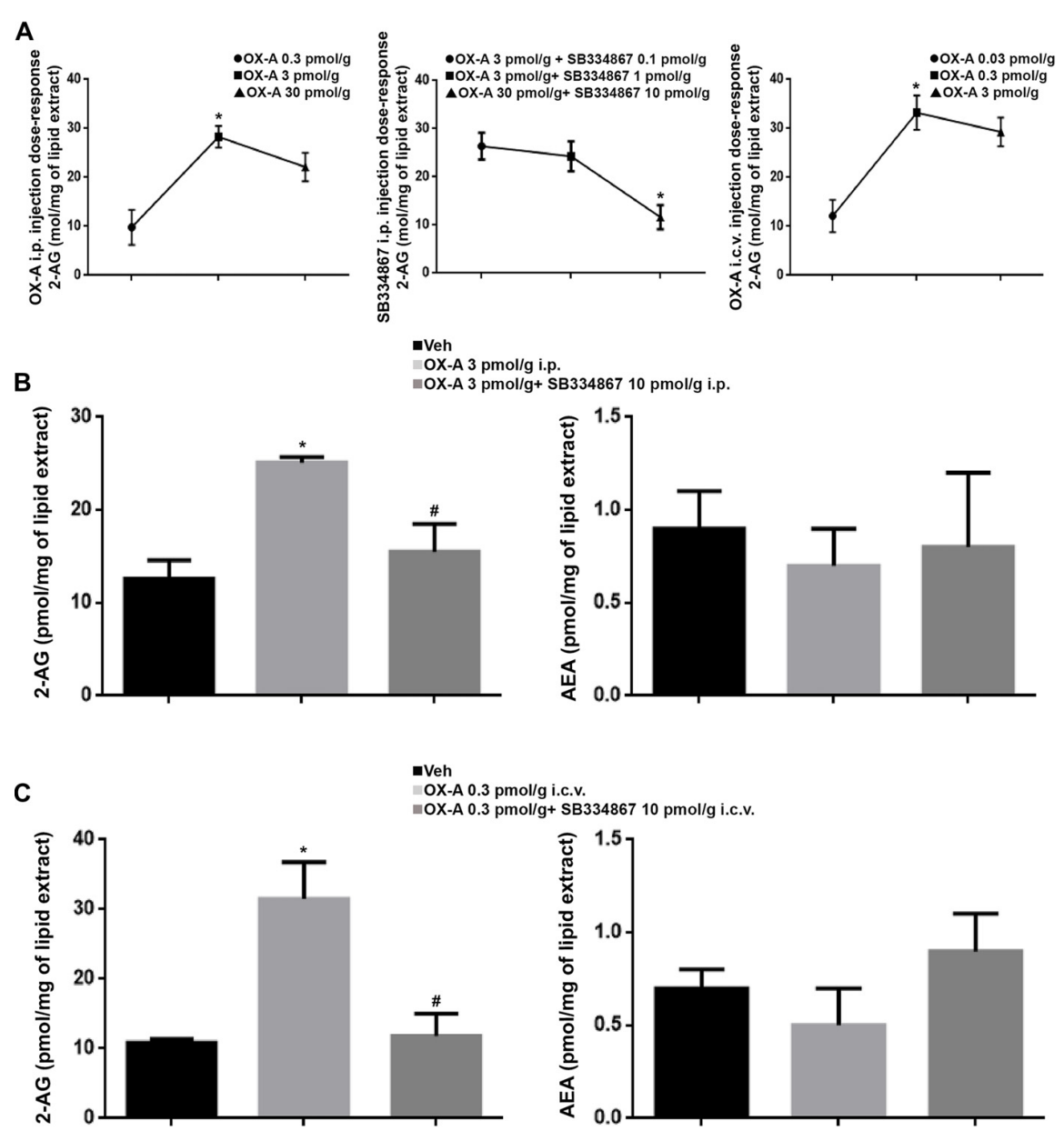

FIGURE 8 | Levels of 2-AG and anandamide (AEA) in the brain of adult zebrafish injected with OX-A and SB334867. (A) Dose-response curve of OX-A and SB334867 i.p. injection and OX-A i.c.v. injection. (B) 2-AG levels, detected using LC-APCI-MS, significantly increased after i.p. injection with OX-A. The increase was prevented by 30 min of pretreatment with SB334867. No significative differences were found for the AEA. (C) 2-AG levels, detected using LC-APCl-MS, significantly increased after i.c.v. injection with OX-A. The increase was prevented by $15 \mathrm{~min}$ of pretreatment with SB334867. No significative differences were found for the AEA. Data are means \pm SEM. ${ }^{*} p<0.05$ vs. ctrl, ${ }^{\#} p<0.05$ vs. OX-A treated.

\section{DISCUSSION}

In the present study, using immunohistochemistry and confocal imaging, we carried out the neuroanatomical mapping of OX$2 \mathrm{R} / \mathrm{CB} 1 \mathrm{R}$ co-expression in the whole zebrafish brain. Since the use of a simpler model, which shows the highly conserved structure and functions, could help bridge the lack of data in shorter times, here we have defined a morphological map of OX2R/CB1R overlapping distributions through the whole zebrafish brain, showing a widespread co-expression of OX-2R and CB1R receptors in numerous brain areas homologous to mammals.

In the telencephalon, OX-2R/CB1R co-expression is intense in the dorsal telencephalic subdivisions Dm and Dl. Such subdivisions are considered as anatomical and functional homologous of the pallial amygdala and part of the hippocampus of mice, respectively (Mueller et al., 2008; Ganz et al., 2014). Behavioral tests after ablation of $\mathrm{Dl}$ or $\mathrm{Dm}$ also support the idea that these structures perform equivalent functions to hippocampus and amygdala of mammals (Rodríguez et al., 2002; Broglio et al., 2005, 2010; Durán et al., 2010). Indeed, the dorsal telencephalic areas are key regulators of sensory, motor, autonomic and endocrine functions, learning and memory and emotion, like the amygdala and hippocampus of mammals. Moreover, it is known that CB1R and OX receptors are expressed in the basolateral amygdala and in the hippocampus of rodents (Matsuda et al., 1993; Peyron et al., 1998; Tsou et al., 1998; Egertová and Elphick, 2000; Marcus et al., 2001). Therefore, the morphological OX-2R/CB1R overlapping distributions found in the $\mathrm{Dm}$ and $\mathrm{Dl}$ of zebrafish supports the homologies between orexins/Ecs interaction in the rodent's homologous brain regions, pointing out their possible involvement in the control of physiological functions regulated by these areas. A similar scenario was found in the subpallium, a region functionally homologous to the mammalian basal ganglia (Cheng et al., 2014), involved in the anxiety-like behaviors, and regulated by orexins and Ecs 
signaling (Nakamachi et al., 2014; Palotai et al., 2014; Imperatore et al., 2015).

Moving on towards the diencephalon, our morphological analysis showed that several other brain regions are characterized by a widespread OX-2R/CB1R anatomical overlapping distributions. The diencephalon of the zebrafish adult brain includes the thalamus, habenula, PO and hypothalamus, all areas highly conserved across the vertebrates (StephensonJones et al., 2011; Cheng et al., 2014). The anterior and dorsal posterior thalamic nuclei seem to correspond, topologically, to the mammalian rostral and caudal thalamus, respectively. On the other hand, the ventral and dorsal habenular nuclei correspond to the mammalian medial and lateral habenular nuclei, respectively (Amo et al., 2010; Mueller, 2012). One of the most important areas of the zebrafish diencephalon is the PO. This area includes the parvocellular and magnocellular preoptic nuclei, and the SC (Braford and Northcutt, 1983; Wullimann et al., 1996; Rupp and Northcutt, 1998; Filippi et al., 2010; Yamamoto et al., 2010, 2011). The magnocellular preoptic nucleus may represent the brain region homologous to the mammalian paraventricular nucleus (PVN), since several neurons express typical PVN neuropeptides (Forlano and Cone, 2007; Machluf et al., 2011). Remarkably, both the magnocellular preoptic nucleus of zebrafish and PVN of mammals play a pivotal role in the control of homeostasis, although they are located respectively in the $\mathrm{PO}$ and hypothalamus (Nieuwenhuys, 2009). In zebrafish, as in all vertebrates, the hypothalamus regulates several physiological and behavioral processes, such as homeostasis, metabolism, energy balance and circadian rhythms (Machluf et al., 2011). Although it has an anatomical organization slightly different from its mammalian counterparts, the hypothalamus of zebrafish contains all the equivalent mammalian hypothalamic cell types located in clusters within the ventral diencephalon (Machluf et al., 2011). The ventral zone of the periventricular hypothalamus in zebrafish is homologous to the hypothalamic arcuate nucleus (Forlano and Cone, 2007; Herget et al., 2014), the main center regulating food intake in mammals. The OX-2R and CB1R anatomical overlapping distributions observed along these diencephalic structures, further reinforce the idea of an orexins/Ecs mediated control of these physiological functions similar in zebrafish and mammals. However, in zebrafish both receptors can be likely expressed in the same or adjacent cell, and future studies can help to elucidate this aspect. Several studies have reported the involvement of orexins/Ecs interactions in the physio-pathological control of homeostasis, food intake and energy balance in mammals (Lau et al., 2017). Indeed, co-localization of these receptors in the hypothalamic area of zebrafish could affect alertness associated to hyperphagic behavior, possibly through the same molecular mechanism described in obese mice, by blunting Pomc gene expression and $\mathrm{POMC} / \alpha-\mathrm{MSH}$ production (Morello et al., 2016).

More caudally, in the diencephalon, OX-2R/CB1R anatomical overlapping distributions has been also observed in other mammalian brain homologous areas. Among these, the PGl and PGm nuclei, which represent the mainly sensory stations projecting to different areas of the pallium and correspond to the mammalian sensory thalamic nuclei (Yamamoto and Ito, 2008; Mueller, 2012).

Finally, TeO, cerebellum and reticular formation are characterized by an intense $\mathrm{OX}-2 \mathrm{R} / \mathrm{CB} 1 \mathrm{R}$ co-expression. The $\mathrm{TeO}$, the main visual center located in the mesencephalon of zebrafish, has been defined as homologous to the cortex of amniotes (Kesavan et al., 2017) or to superior colliculus of mammals (Heap et al., 2018), important structures involved in the control of visual functions and movement coordination (Mueller, 2012). The cerebellum and the reticular formation are two main structures of the rhombencephalon, the most evolutionarily and morphologically ancient part of the brain, neuroanatomically and molecularly highly conserved across vertebrates (Gilland and Baker, 1993). The cerebellum is involved in the control of coordinated movement, as in mammals, whereas the corporation of cell groups which form the reticular formation is involved in the control of wakefulness (Moens and Prince, 2002). Therefore, physiological functions, such as wakefulness and locomotion, which are under the control of both, orexins and Ecs signaling, are regulated in zebrafish by brain structures morphologically and functionally highly conserved.

The anatomical OX-2R/CB1R overlapping distributions, observed in numerous zebrafish brain areas, were found to be accompanied by functional $\mathrm{OX}-2 \mathrm{R} / \mathrm{CB} 1 \mathrm{R}$ interaction, as revealed by biochemical quantification of the tissue levels of the endocannabinoid 2-AG. At this purpose, we used synthetic human OX-A known to have effective physiological activity in zebrafish and goldfish (Miura et al., 2007; Yokogawa et al., 2007; Facciolo et al., 2009, 2011; Yokobori et al., 2011). We found that the OX-A-mediated OX-2R activation in the brain of adult zebrafish, like in the rodent brain (Ho et al., 2011; Cristino et al., 2013, 2016; Morello et al., 2016), leads to an increase of 2-AG biosynthesis which can be blocked by the antagonism of the OX-2R. Though the SB334867 is not entirely selective for OX receptors and has been reported to be hydrolytically unstable, this compound seems suppress the action of OX-A, suggesting that in zebrafish SB334867 antagonizes orexin at the OX-2R, the only identified orexin receptor in fish (Wong et al., 2011). These findings further support the hypothesis that the orexins/Ecs signaling interaction in the brain of adult zebrafish is similar to that previously found to occur in those regions of the mammalian brain where the two receptors are contiguous. In the murine brain, $\mathrm{OX}-1 \mathrm{R}$ activity releases high levels of 2$\mathrm{AG}$, which acts as a potent autocrine or paracrine messenger stimulating the same or the neighboring CB1R-expressing cells, respectively (Cristino et al., 2013, 2016, 2017; Imperatore et al., 2016; Morello et al., 2016). The orexins and Ecs signaling interaction in the rodent hypothalamic and extra-hypothalamic areas regulates energy homeostasis (Cristino et al., 2013, 2016, 2017; Morello et al., 2016), nociception (Ho et al., 2011; Cristino et al., 2016, 2017), reward and seeking behaviors (Flores et al., 2013). Moreover, sleep/wake transition, arousal and appetite seem to be affected by changes of OX-A levels accompanied by an increase in 2-AG levels in the same hypothalamic area (Cristino et al., 2013; Kukkonen, 2013; Morello et al., 2016). However, numerous data about the role of orexins/Ecs signaling 
interaction in the control of physiological functions are still lacking.

Since the assessment of the anatomical distribution of a receptor can provide information on its physiological role, the anatomical map of OX-2R/CB1R overlapping distributions in the whole zebrafish brain, accompanied by the functional interaction of the two receptors, both reported here for the first time, opens the way to the future use of zebrafish as animal models for the analysis of the complex brain functions (including, for example, modulation of appetite, sleep-wake cycle, learning and memory, locomotor activity) regulated by the orexins/Ecs signaling interaction, and of their dysregulation in disease.

\section{AUTHOR CONTRIBUTIONS}

RI and LD'A designed the experiment, carried out tissue processing, immunohistochemistry, and analyzed the data. OS and HAM designed the experiment and took care of the

\section{REFERENCES}

Alvarez, C. E., and Sutcliffe, J. G. (2002). Hypocretin is an early member of the incretin gene family. Neurosci. Lett. 324, 169-172. doi: 10.1016/s03043940(02)00195-7

Amo, R., Aizawa, H., Takahoko, M., Kobayashi, M., Takahashi, R., Aoki, T., et al. (2010). Identification of the zebrafish ventral habenula as a homolog of the mammalian lateral habenula. J. Neurosci. 30, 1566-1574. doi: 10.1523/JNEUROSCI.3690-09.2010

Braford, M., and Northcutt, R. (1983). "Organization of the diencephalon and pretectum of the ray-finned fishes," in Fish Neurobiology, eds D. Re and N. Rg (Ann Arbor, MI: University of Michigan Press), 117-140.

Broglio, C., Gómez, A., Durán, E., Ocaña, F. M., Jiménez-Moya, F., Rodríguez, F., et al. (2005). Hallmarks of a common forebrain vertebrate plan: specialized pallial areas for spatial, temporal and emotional memory in actinopterygian fish. Brain Res. Bull. 66, 277-281. doi: 10.1016/j.brainresbull. 2005.03.021

Broglio, C., Rodríguez, F., Gómez, A., Arias, J. L., and Salas, C. (2010). Selective involvement of the goldfish lateral pallium in spatial memory. Behav. Brain Res. 210, 191-201. doi: 10.1016/j.bbr.2010.02.031

Cheng, R. K., Jesuthasan, S. J., and Penney, T. B. (2014). Zebrafish forebrain and temporal conditioning. Philos. Trans. R. Soc. Lond. B Biol. Sci. 369:20120462. doi: $10.1098 / \mathrm{rstb} .2012 .0462$

Chiu, C. N., and Prober, D. A. (2013). Regulation of zebrafish sleep and arousal states: current and prospective approaches. Front. Neural Circuits 7:58. doi: 10.3389/fncir.2013.00058

Cristino, L., Busetto, G., Imperatore, R., Ferrandino, I., Palomba, L., Silvestri, C., et al. (2013). Obesity-driven synaptic remodeling affects endocannabinoid control of orexinergic neurons. Proc. Natl. Acad. Sci. U S A 110, E2229-E2238. doi: 10.1073/pnas.1219485110

Cristino, L., Imperatore, R., Palomba, L., and Di Marzo, V. (2017). "The endocannabinoid system in leptin-driven changes of Orexinergic signalling under physiological and pathological conditions," in Endocannabinoids and Lipid Mediators in Brain Functions, ed. M. Melis (Cham: Springer), $1-26$.

Cristino, L., Luongo, L., Imperatore, R., Boccella, S., Becker, T., Morello, G., et al. (2016). Orexin-A and endocannabinoid activation of the descending antinociceptive pathway underlies altered pain perception in leptin signaling deficiency. Neuropsychopharmacology 41, 508-520. doi: 10.1038/npp. 2015.173

D’Angelo, L., Lossi, L., Merighi, A., and de Girolamo, P. (2016a). Anatomical features for the adequate choice of experimental animal models in biomedicine: I. Fishes. Ann. Anat. 205, 75-84. doi: 10.1016/j.aanat.2016. 02.001 animal husbandry. FP carried out the lipid extraction and the measurement of 2-AG levels in the brain. PG analyzed the data and wrote the manuscript. LC and EV carried out tissue processing and immunohistochemistry. VM analyzed the data. MP designed the experiment, analyzed the data and wrote the manuscript.

\section{FUNDING}

This study was supported by Fondi Ricerca di Ateneo (FRA) 2015-2016, University of Sannio and by DR/2017/409-Project F.I.A.T., University of Naples Federico II.

\section{SUPPLEMENTARY MATERIAL}

The Supplementary Material for this article can be found online at: https://www.frontiersin.org/articles/10.3389/fnana.2018.000 62/full\#supplementary-material

D’Angelo, L., Castaldo, L., de Girolamo, P., Lucini, C., Paolucci, M., Pelagalli, A., et al. (2016b). Orexins and receptor OX2R in the gastroenteric apparatus of two teleostean species: Dicentrarchus labrax and Carassius auratus. Anat. Rec. 299, 1121-1129. doi: 10.1002/ar.23374

Darker, J. G., Porter, R. A., Eggleston, D. S., Smart, D., Brough, S. J., SabidoDavid, C., et al. (2001). Structure-activity analysis of truncated orexin-A analogues at the orexin-1 receptor. Bioorg. Med. Chem. Lett. 11, 737-740. doi: $10.1016 / \mathrm{s} 0960-894 \mathrm{x}(01) 00043-9$

de Lecea, L., Kilduff, T. S., Peyron, C., Gao, X., Foye, P. E., Danielson, P. E., et al. (1998). The hypocretins: hypothalamus-specific peptides with neuroexcitatory activity. Proc. Natl. Acad. Sci. U S A 95, 322-327. doi: 10.1073/pnas. 95.1.322

Durán, E., Ocaña, F. M., Broglio, C., Rodríguez, F., and Salas, C. (2010). Lateral but not medial telencephalic pallium ablation impairs the use of goldfish spatial allocentric strategies in a "hole-board" task. Behav. Brain Res. 214, 480-487. doi: 10.1016/j.bbr.2010.06.010

Egertová, M., and Elphick, M. R. (2000). Localisation of cannabinoid receptors in the rat brain using antibodies to the intracellular C-terminal tail of CB. J. Comp. Neurol. 422, 159-171. doi: 10.1002/(sici)1096-9861(20000626)422:2<159::aidcne $1>3.0$. co; $2-1$

Elbaz, I., Foulkes, N. S., Gothilf, Y., and Appelbaum, L. (2013). Circadian clocks, rhythmic synaptic plasticity and the sleep-wake cycle in zebrafish. Front. Neural Circuits 7:9. doi: 10.3389/fncir.2013.00009

Esmaeili, M.-H., Reisi, Z., Ezzatpanah, S., and Haghparast, A. (2017). Role of orexin-2 and CB1 receptors within the periaqueductal gray matter in lateral hypothalamic-induced antinociception in rats. Behav. Pharmacol. 28, 83-89. doi: 10.1097/FBP.0000000000000277

Facciolo, R. M., Crudo, M., Giusi, G., Alò, R., and Canonaco, M. (2009). Light- and dark-dependent orexinergic neuronal signals promote neurodegenerative phenomena accounting for distinct behavioral responses in the teleost Thalassoma pavo. J. Neurosci. Res. 87, 748-757. doi: 10.1002/jnr. 21886

Facciolo, R. M., Crudo, M., Zizza, M., Giusi, G., and Canonaco, M. (2011). Feeding behaviors and ORXR- $\beta$-GABA A R subunit interactions in Carassius auratus. Neurotoxicol. Teratol. 33, 641-650. doi: 10.1016/j.ntt.2011.09.008

Faraco, J. H., Appelbaum, L., Marin, W., Gaus, S. E., Mourrain, P., and Mignot, E. (2006). Regulation of hypocretin (orexin) expression in embryonic zebrafish. J. Biol. Chem. 281, 29753-29761. doi: 10.1074/jbc.M605 811200

Filippi, A., Mahler, J., Schweitzer, J., and Driever, W. (2010). Expression of the paralogous tyrosine hydroxylase encoding genes th1 and th2 reveals the full complement of dopaminergic and noradrenergic neurons in zebrafish larval and juvenile brain. J. Comp. Neurol. 518, 423-438. doi: 10.1002/cne. 22213 
Flores, A., Maldonado, R., and Berrendero, F. (2013). Cannabinoid-hypocretin cross-talk in the central nervous system: what we know so far. Front. Neurosci. 7:256. doi: $10.3389 /$ fnins.2013.00256

Forlano, P. M., and Cone, R. D. (2007). Conserved neurochemical pathways involved in hypothalamic control of energy homeostasis. J. Comp. Neurol. 505, 235-248. doi: 10.1002/cne.21447

Galas, L., Vaudry, H., Braun, B., van den Pol, A. N., de Lecea, L., Sutcliffe, J. G., et al. (2001). Immunohistochemical localization and biochemical characterization of hypocretin/orexin-related peptides in the central nervous system of the frog Rana ridibunda. J. Comp. Neurol. 429, 242-252. doi: 10.1002/1096-9861(20000108)429:2<242::aid-cne5>3. $0 . \operatorname{co} ; 2-\mathrm{Z}$

Ganz, J., Kroehne, V., Freudenreich, D., Machate, A., Geffarth, M., Braasch, I., et al. (2014). Subdivisions of the adult zebrafish pallium based on molecular marker analysis. F1000Res. 3:308. doi: 10.12688/f1000research. 5595.2

Gary-Bobo, M., Elachouri, G., Gallas, J. F., Janiak, P., Marini, P., RavinetTrillou, C., et al. (2007). Rimonabant reduces obesity-associated hepatic steatosis and features of metabolic syndrome in obese Zucker fa/fa rats. Hepatology 46, 122-129. doi: 10.1002/hep.21641

Gilland, E., and Baker, R. (1993). Conservation of neuroepithelial and mesodermal segments in the embryonic vertebrate head. Acta Anat. 148, 110-123. doi: 10.1159/000147530

Haffter, P., and Nüsslein-Volhard, C. (1996). Large scale genetics in a small vertebrate, the zebrafish. Int. J. Dev. Biol. 40, 221-227.

Heap, L. A., Vanwalleghem, G. C., Thompson, A. W., Favre-Bulle, I., RubinszteinDunlop, H., and Scott, E. K. (2018). Hypothalamic projections to the optic tectum in larval zebrafish. Front. Neuroanat. 11:135. doi: 10.3389/fnana.2017. 00135

Herget, U., Wolf, A., Wullimann, M. F., and Ryu, S. (2014). Molecular neuroanatomy and chemoarchitecture of the neurosecretory preoptichypothalamic area in zebrafish larvae. J. Comp. Neurol. 522, 1542-1564. doi: 10.1002/cne.23480

Herkenham, M., Lynn, A. B., Johnson, M. R., Melvin, L. S., de Costa, B. R., and Rice, K. C. (1991). Characterization and localization of cannabinoid receptors in rat brain: a quantitative in vitro autoradiographic study. J. Neurosci. 11, 563-583. doi: 10.1523/JNEUROSCI.11-02-00563.1991

Herkenham, M., Lynn, A. B., Little, M. D., Johnson, M. R., Melvin, L. S., de Costa, B. R., et al. (1990). Cannabinoid receptor localization in brain. Proc. Natl. Acad. Sci. U S A 87, 1932-1936. doi: 10.1073/pnas.87.5.1932

Ho, Y. C., Lee, H. J., Tung, L. W., Liao, Y. Y., Fu, S. Y., Teng, S. F., et al. (2011). Activation of orexin 1 receptors in the periaqueductal gray of male rats leads to anti-nociception via retrograde endocannabinoid(2-arachidonoylglycerol)induced disinhibition. J. Neurosci. 31, 14600-14610. doi: 10.1523/JNEUROSCI. 2671-11.2011

Hungs, M., Fan, J., Lin, L., Lin, X., Maki, R. A., and Mignot, E. (2001). Identification and functional analysis of mutations in the hypocretin (orexin) genes of narcoleptic canines. Genome Res. 11, 531-539. doi: 10.1101/gr.gr$1610 \mathrm{r}$

Imperatore, R., Morello, G., Luongo, L., Taschler, U., Romano, R., De Gregorio, D., et al. (2015). Genetic deletion of monoacylglycerol lipase leads to impaired cannabinoid receptor $\mathrm{CB}_{1} \mathrm{R}$ signaling and anxiety-like behavior. J. Neurochem. 135, 799-813. doi: 10.1111/jnc.13267

Imperatore, R., Palomba, L., Morello, G., Spiezio, A. D., Piscitelli, F., Marzo, V. D., et al. (2016). Formation of OX-1R/CB1R heteromeric complexes in embryonic mouse hypothalamic cells: effect on intracellular calcium, 2-arachidonoylglycerol biosynthesis and ERK phosphorylation. Pharmacol. Res. 111, 600-609. doi: 10.1016/j.phrs.2016.07.009

Kaslin, J., Nystedt, J. M., Östergård, M., Peitsaro, N., and Panula, P. (2004). The orexin/hypocretin system in zebrafish is connected to the aminergic and cholinergic systems. J. Neurosci. 24, 2678-2689. doi: 10.1523/JNEUROSCI. 4908-03.2004

Kesavan, G., Chekuru, A., Machate, A., and Brand, M. (2017). CRISPR/Cas9mediated zebrafish knock-in as a novel strategy to study midbrain-hindbrain boundary development. Front. Neuroanat. 11:52. doi: 10.3389/fnana.2017. 00052

Klee, E. W., Schneider, H., Clark, K. J., Cousin, M. A., Ebbert, J. O., and Hooten, W. M. (2012). Zebrafish: a model for the study of addiction genetics. Hum. Genet. 131, 977-1008. doi: 10.1007/s00439-011-1128-0
Krug, R. G. II., and Clark, K. J. (2015). Elucidating cannabinoid biology in zebrafish (Danio rerio). Gene 570, 168-179. doi: 10.1016/j.gene. 2015.07.036

Kukkonen, J. P. (2013). Physiology of the orexinergic/hypocretinergic system: a revisit in 2012. Am J. Physiol. Cell. Physiol. 304, C2-C32. doi: 10.1152/ajpcell. 00227.2012

Lam, C. S., Rastegar, S., and Strähle, U. (2006). Distribution of cannabinoid receptor 1 in the CNS of zebrafish. Neuroscience 138, 83-95. doi: 10.1016/j. neuroscience.2005.10.069

Lang, M., Söll, R. M., Dürrenberger, F., Dautzenberg, F. M., and BeckSickinger, A. G. (2004). Structure-activity studies of orexin a and orexin $\mathrm{B}$ at the human orexin 1 and orexin 2 receptors led to orexin 2 receptor selective and orexin 1 receptor preferring ligands. J. Med. Chem. 47, 1153-1160. doi: $10.1021 / \mathrm{jm} 030982 \mathrm{t}$

Lau, B. K., Cota, D., Cristino, L., and Borgland, S. L. (2017). Endocannabinoid modulation of homeostatic and non-homeostatic feeding circuits. Neuropharmacology 124, 38-51. doi: 10.1016/j.neuropharm.2017.05.033

Leung, L. C., Wang, G. X., and Mourrain, P. (2013). Imaging zebrafish neural circuitry from whole brain to synapse. Front. Neural Circuits 7:76. doi: 10.3389/fncir.2013.00076

Machluf, Y., Gutnick, A., and Levkowitz, G. (2011). Development of the zebrafish hypothalamus. Ann. N Y Acad. Sci. 1220, 93-105. doi: 10.1111/j.1749-6632. 2010.05945.x

Marcus, J. N., Aschkenasi, C. J., Lee, C. E., Chemelli, R. M., Saper, C. B., Yanagisawa, M., et al. (2001). Differential expression of orexin receptors 1 and 2 in the rat brain. J. Comp. Neurol. 435, 6-25. doi: 10.1002/ cne. 1190

Matsuda, L. A., Bonner, T. I., and Lolait, S. J. (1993). Localization of cannabinoid receptor mRNA in rat brain. J. Comp. Neurol. 327, 535-550. doi: 10.1002/cne. 903270406

McPartland, J. M., and Glass, M. (2003). Functional mapping of cannabinoid receptor homologs in mammals, other vertebrates, and invertebrates. Gene 312, 297-303. doi: 10.1016/s0378-1119(03)00638-3

McPartland, J. M., Glass, M., Matias, I., Norris, R. W., and Kilpatrick, C. W. (2007). A shifted repertoire of endocannabinoid genes in the zebrafish (Danio rerio). Mol. Genet. Genomics 277, 555-570. doi: 10.1007/s00438-0070207-3

Miura, T., Maruyama, K., Shimakura, S., Kaiya, H., Uchiyama, M., Kangawa, K., et al. (2007). Regulation of food intake in the goldfish by interaction between ghrelin and orexin. Peptides 28, 1207-1213. doi: 10.1016/j.peptides. 2007.03.023

Moens, C. B., and Prince, V. E. (2002). Constructing the hindbrain: insights from the zebrafish. Dev. Dyn. 224, 1-17. doi: 10.1002/dvdy.10086

Morello, G., Imperatore, R., Palomba, L., Finelli, C., Labruna, G., Pasanisi, F., et al. (2016). Orexin-A represses satiety-inducing POMC neurons and contributes to obesity via stimulation of endocannabinoid signaling. Proc. Natl. Acad. Sci. U S A 113, 4759-4764. doi: 10.1073/pnas.1521 304113

Mueller, T. (2012). What is the thalamus in zebrafish? Front. Neurosci. 6:64. doi: 10.3389/fnins.2012.00064

Mueller, T., and Wullimann, M. F. (2009). An evolutionary interpretation of teleostean forebrain anatomy. Brain Behav. Evol. 74, 30-42. doi: 10.1159/000229011

Mueller, T., Wullimann, M. F., and Guo, S. (2008). Early teleostean basal ganglia development visualized by zebrafish Dlx2a, Lhx6, Lhx7, Tbr2 (eomesa), and GAD67 gene expression. J. Comp. Neurol. 507, 1245-1257. doi: 10.1002/cne. 21604

Nakamachi, T., Matsuda, K., Maruyama, K., Miura, T., Uchiyama, M., Funahashi, H., et al. (2006). Regulation by orexin of feeding behaviour and locomotor activity in the goldfish. J. Neuroendocrinol. 18, 290-297. doi: 10.1111/j.1365-2826.2006.01415.x

Nakamachi, T., Shibata, H., Sakashita, A., Iinuma, N., Wada, K., Konno, N., et al. (2014). Orexin A enhances locomotor activity and induces anxiogenic-like action in the goldfish, Carassius auratus. Horm. Behav. 66, 317-323. doi: 10.1016/j.yhbeh.2014.06.004

Nieuwenhuys, R. (2009). The forebrain of actinopterygians revisited. Brain Behav. Evol. 73, 229-252. doi: 10.1159/000225622

Norton, W., and Bally-Cuif, L. (2010). Adult zebrafish as a model organism for behavioural genetics. BMC Neurosci. 11:90. doi: 10.1186/1471-2202-11-90 
Novak, C. M., Jiang, X., Wang, C., Teske, J. A., Kotz, C. M., and Levine, J. A. (2005). Calorie restriction and physical activity in zebrafish (Danio rerio). Neurosci. Lett. 383, 99-104. doi: 10.1016/j.neulet.2005. 03.048

Ohkubo, T., Boswell, T., and Lumineau, S. (2002). Molecular cloning of chicken prepro-orexincDNAand preferential expression in the chicken hypothalamus. Biochim. Biophys. Acta 1577, 476-480. doi: 10.1016/s0167-4781(02) 00483-9

Osei-Hyiaman, D., DePetrillo, M., Pacher, P., Liu, J., Radaeva, S., Bátkai, S., et al. (2005). Endocannabinoid activation at hepatic CB1 receptors stimulates fatty acid synthesis and contributes to diet-induced obesity. J. Clin. Invest. 115, 1298-1305. doi: 10.1172/jci23057

Palotai, M., Telegdy, G., and Jászberényi, M. (2014). Orexin A-induced anxiety-like behavior is mediated through GABA-ergic, $\alpha$ - and $\beta$-adrenergic neurotransmissions in mice. Peptides 57, 129-134. doi: 10.1016/j.peptides.2014. 05.003

Panula, P. (2010). Hypocretin/orexin in fish physiology with emphasis on zebrafish. Acta Physiol. 198, 381-386. doi: 10.1111/j.1748-1716.2009. 02038.x

Panula, P., Chen, Y. C., Priyadarshini, M., Kudo, H., Semenova, S., Sundvik, M., et al. (2010). The comparative neuroanatomy and neurochemistry of zebrafish CNS systems of relevance to human neuropsychiatric diseases. Neurobiol. Dis. 40, 46-57. doi: 10.1016/j.nbd.2010.05.010

Pertwee, R. G. (1997). Pharmacology of cannabinoid CB1 and CB2 receptors. Pharmacol. Ther. 74, 129-180. doi: 10.1016/s0163-7258(97) 82001-3

Peyron, C., Tighe, D. K., van den Pol, A. N., de Lecea, L., Heller, H. C., Sutcliffe, J. G., et al. (1998). Neurons containing hypocretin (orexin) project to multiple neuronal systems. J. Neurosci. 18, 9996-10015. doi: 10.1523/JNEUROSCI.18-23-09996.1998

Piomelli, D. (2003). The molecular logic of endocannabinoid signalling. Nat. Rev. Neurosci. 4, 873-884. doi: 10.1038/nrn1247

Prober, D. A., Rihel, J., Onah, A. A., Sung, R. J., and Schier, A. F. (2006). Hypocretin/orexin overexpression induces an insomnia-like phenotype in zebrafish. J. Neurosci. 26, 13400-13410. doi: 10.1523/JNEUROSCI.4332-06. 2006

Rodríguez, F., López, J. C., Vargas, J. P., Broglio, C., Gómez, Y., and Salas, C. (2002). Spatial memory and hippocampal pallium through vertebrate evolution: insights from reptiles and teleost fish. Brain Res. Bull. 57, 499-503. doi: 10.1016/s0361-9230(01)00682-7

Rupp, B., and Northcutt, R. G. (1998). The diencephalon and pretectum of the white sturgeon (Acipenser transmontanus): a cytoarchitectonic study. Brain Behav. Evol. 51, 239-262. doi: 10.1159/000006541

Rupp, B., Wullimann, M. F., and Reichert, H. (1996). The zebrafish brain: a neuroanatomical comparison with the goldfish. Anat. Embryol. 194, 187-203. doi: 10.1007/bf00195012

Sakurai, T., Amemiya, A., Ishii, M., Matsuzaki, I., Chemelli, R. M., Tanaka, H., et al. (1998). Orexins and orexin receptors: a family of hypothalamic neuropeptides and G-protein-coupled receptors that regulate feeding behavior. Cell 92, 573-585. doi: 10.1016/S0092-8674(00)80949-6

Shibahara, M., Sakurai, T., Nambu, T., Takenouchi, T., Iwaasa, H., Egashira, S. I., et al. (1999). Structure, tissue distribution, and pharmacological characterization of Xenopus orexins. Peptides 20, 1169-1176. doi: 10.1016/s0196-9781(99)00120-5

Shimada, Y., Hirano, M., Nishimura, Y., and Tanaka, T. (2012). A high-throughput fluorescence-based assay system for appetite-regulating gene and drug screening. PLoS One 7:e52549. doi: 10.1371/journal.pone. 0052549

Silvestri, C., and Di Marzo, V. (2013). The endocannabinoid system in energy homeostasis and the etiopathology of metabolic disorders. Cell Metab. 17, 475-490. doi: 10.1016/j.cmet.2013.03.001

Singh, C., Oikonomou, G., and Prober, D. A. (2015). Norepinephrine is required to promote wakefulness and for hypocretin-induced arousal in zebrafish. Elife 4:e07000. doi: 10.7554/eLife.07000

Stephenson-Jones, M., Floros, O., Robertson, B., and Grillner, S. (2011). Evolutionary conservation of the habenula nuclei and their circuitry controlling the dopamine and 5-hydroxytryptophan (5-HT) systems. Proc. Natl. Acad. Sci. U S A 109, E164-E173. doi: 10.1073/pnas.1119348109
Sundvik, M., Kudo, H., Toivonen, P., Rozov, S., Chen, Y. C., and Panula, P. (2011). The histaminergic system regulates wakefulness and orexin/hypocretin neuron development via histamine receptor $\mathrm{H} 1$ in zebrafish. FASEB J. 25, 4338-4347. doi: 10.1096/fj.11-188268

Sundvik, M., and Panula, P. (2015). Interactions of the orexin/hypocretin neurones and the histaminergic system. Acta Physiol. 213, 321-333. doi: 10.1111/apha. 12432

Tsou, K., Brown, S., Sañudo-Peña, M. C., Mackie, K., and Walker, J. M. (1998). Immunohistochemical distribution of cannabinoid CB1 receptors in the rat central nervous system. Neuroscience 83, 393-411. doi: 10.1016/s03064522(97)00436-3

Tsujino, N., and Sakurai, T. (2013). Role of orexin in modulating arousal, feeding, and motivation. Front. Behav. Neurosci. 7:28. doi: 10.3389/fnbeh.2013. 00028

Varshney, G. K., and Burgess, S. M. (2014). Mutagenesis and phenotyping resources in zebrafish for studying development and human disease. Brief. Funct. Genomics. 13, 82-94. doi: 10.1093/bfgp/elt042

Volkoff, H., Bjorklund, J. M., and Peter, R. E. (1999). Stimulation of feeding behavior and food consumption in the goldfish, Carassius auratus, by orexin-A and orexin-B. Brain Res. 846, 204-209. doi: 10.1016/s0006-8993(99) 02052-1

Volkoff, H., Eykelbosh, A. J., and Peter, R. E. (2003). Role of leptin in the control of feeding of goldfish Carassius auratus: interactions with cholecystokinin, neuropeptide $\mathrm{Y}$ and orexin A, and modulation by fasting. Brain Res. 972, 90-109. doi: 10.1016/S0006-8993(03)02507-1

Volkoff, H., and Peter, R. E. (2000). Effects of CART peptides on food consumption, feeding and associated behaviors in the goldfish, Carassius auratus: actions on neuropeptide $\mathrm{Y}$ - and orexin A-induced feeding. Brain Res. 887, 125-133. doi: 10.1016/S0006-8993(00) 03001-8

Volkoff, H., and Peter, R. E. (2001). Interactions between orexin A, NPY and galanin in the control of food intake of the goldfish, Carassius auratus. Regul Pept. 101, 59-72. doi: 10.1016/S0167-0115(01) 00261-0

Wolman, M., and Granato, M. (2012). Behavioral genetics in larval zebrafish: learning from the young. Dev. Neurobiol. 72, 366-372. doi: 10.1002/dneu. 20872

Wong, K. K. Y., Ng, S. Y. L., Lee, L. T. O., Ng, H. K. H., and Chow, B. K. C. (2011). Orexins and their receptors from fish to mammals: a comparative approach. Gen. Comp. Endocrinol. 171, 124-130. doi: 10.1016/j.ygcen.2011. 01.001

Wullimann, M. F., and Mueller, T. (2004). Teleostean and mammalian forebrains contrasted: evidence from genes to behavior. J. Comp. Neurol. 475, 143-162. doi: 10.1002/cne.20183

Wullimann, M. F., Rupp, B., and Reichert, H. (1996). Neuroanatomy of the Zebrafish Brain: A Topological Atlas. Basel: Birkhäuser.

$\mathrm{Xu}$, M., and Volkoff, H. (2007). Molecular characterization of prepro-orexin in Atlantic cod (Gadus morhua): cloning, localization, developmental profile and role in food intake regulation. Mol. Cell Endocrinol. 271, 28-37. doi: 10.1016/j. mce.2007.03.003

Yamamoto, N., and Ito, H. (2008). Visual, lateral line, and auditory ascending pathways to the dorsal Telencephalic are a through the rostro lateral region of the lateral preglomerular nucleus in cyprinids. J. Comp. Neurol. 508, 615-647. doi: 10.1002/cne.21717

Yamamoto, K., Ruuskanen, J. O., Wullimann, M. F., and Vernier, P. (2010). Two tyrosine hydroxylases in vertebrates: new dopaminergic territories revealed in the adult zebrafish brain. Mol. Cell. Neurosci. 43, 394-402. doi: 10.1016/j.mcn. 2010.01.006

Yamamoto, K., Ruuskanen, J. O., Wullimann, M. F., and Vernier, P. (2011). Differential expression of dopaminergic cell markers in the adult zebrafish forebrain. J. Comp. Neurol. 519, 576-598. doi: 10.1002/cne. 22535

Yazdi, F., Jahangirvand, M., Pirasteh, A. H., Moradi, M., and Haghparast, A. (2015). Functional interaction between OX2 and CB1 receptors in the ventral tegmental area and the nucleus accumbens in response to place preference induced by chemical stimulation of the lateral hypothalamus. Pharmacol. Biochem. Behav. 139, 39-46. doi: 10.1016/j.pbb.2015. 10.012 
Yokobori, E., Kojima, K., Azuma, M., Kang, K. S., Maejima, S., Uchiyama, M., et al. (2011). Stimulatory effect of intracerebroventricular administration of orexin A on food intake in the zebrafish, Danio rerio. Peptides 32, 1357-1362. doi: 10.1016/j.peptides.2011.05.010

Yokogawa, T., Marin, W., Faraco, J., Pézeron, G., Appelbaum, L., Zhang, J., et al. (2007). Characterization of sleep in zebrafish and insomnia in hypocretin receptor mutants. PLoS Biol. 5:e277. doi: 10.1371/journal.pbio. 0050277

Zou, S., and Kumar, U. (2018). Cannabinoid receptors and the endocannabinoid system: signaling and function in the central nervous system. Int. J. Mol. Sci. 19:E833. doi: 10.3390/ijms19030833
Conflict of Interest Statement: The authors declare that the research was conducted in the absence of any commercial or financial relationships that could be construed as a potential conflict of interest.

Copyright $\odot 2018$ Imperatore, D’Angelo, Safari, Motlagh, Piscitelli, de Girolamo, Cristino, Varricchio, di Marzo and Paolucci. This is an open-access article distributed under the terms of the Creative Commons Attribution License (CC BY). The use, distribution or reproduction in other forums is permitted, provided the original author(s) and the copyright owner(s) are credited and that the original publication in this journal is cited, in accordance with accepted academic practice. No use, distribution or reproduction is permitted which does not comply with these terms. 